\title{
Predictability and Habit Persistence
}

\author{
Fabrice Collard \\ University of Toulouse (CNRS-GREMAQ and IDEI) \\ Patrick Fève* \\ University of Toulouse (CNRS-GREMAQ and IDEI) \\ Banque de France \\ Imen Ghattassi \\ University of Toulouse (GREMAQ)
}

June 1, 2005

\begin{abstract}
This paper develops a capital asset pricing model à la Lucas with habit formation when the growth rate of endowment follows a first order Gaussian autoregression. We provide a closed form solution of the price-dividend ratio and determine conditions that guarantee the existence of a bounded equilibrium. The habit stock model is found to possess internal propagation mechanisms that (i) amplify the effects of shocks to endowment and (ii) increase the persistence. These features imply that, although risk aversion is not time-varying and all investors are identical, the model can solve the predictability puzzle.
\end{abstract}

Key Words: Asset Pricing, Catching up with the Joneses, Habit Stock, Predictability

JEL Class.: C62, G12.

*Corresponding author: GREMAQ-Université de Toulouse 1, 21 allée de Brienne, 31000 Toulouse, France. Tel: (33) 5-61-12-85-75, Fax: (33) 5-61-22-55-63. Email: patrick.feve@univ-tlse1.fr 


\section{Introduction}

Over the last 20 years, the predictability of excess stock returns has attracted a great deal of attention. Recent empirical work reports evidence suggesting that excess returns are at least partially predictable. The initial piece of evidence in favor of predictability was obtained by examining univariate time series properties (see e.g. Poterba and Summers [1988]). The literature has also reported convincing evidence that financial and accounting variables have predictive power for stock returns (See Fama and French [1988], Fama and French [1989], Campbell and Shiller [1988], Hodrick [1992], Campbell, Lo and MacKinlay [1997], Cochrane [1997,2001], Lamont [1998], Lettau and Ludvigson [2001] and Campbell [2003]). This work has spread to the macroeconomic literature that has shown that excess returns can be predicted by macroeconomic variables that describe the business cycle. The equity premium is found to be correlated with the business cycle, expected excess returns and conditional returns volatility are time-varying and move countercyclically. It was therefore natural for the macroeconomic literature to gauge the ability of the standard consumption based capital asset pricing model to account for this predictability. But the model - in its basic time separable version - fails to account for this set of stylized facts, giving rise to a predictability puzzle. This paper explicitly investigates this issue, and gauge the ability of a "catching up with the Joneses" model augmented for habit stock to solve the puzzle.

As aforementioned the standard consumption based capital asset pricing model (CCAPM) fails to account for the predictability puzzle. This finding is now well established in the literature and essentially stems from the inability of the model with time separable utility to generate enough persistence. Excess return essentially behave as iid stochastic processes, unless strong persistence is added to the shocks initiating fluctuations on the asset market. Therefore, neither do they exhibit serial correlation nor are they strongly related to other variables. Not to say that the CCAPM is useless for explaining asset prices. Recent theoretical work has shown that the CCAPM can generate predictability of excess returns providing the basic model is amended (see Campbell [2003] for a survey). This work includes models with heterogenous investors (see Chan and Kogan [2001]) or models with time varying risk aversion generated by habit formation (see Campbell and Cochrane [1999], Menzly, Santos and Veronesi [2004]). This paper will partially pursue this latter route and consider a habit formation model. It should be noted that the literature dealing with habit formation falls into two broad categories. On the one hand, 
internal habit formation captures the influence of individual's own past consumption on the individual current consumption choice (see Boldrin, Christiano and Fisher [1997]). On the other hand, external habit formation captures the influence of the aggregate past consumption choices on the current individual consumption choices (Abel [1990]). This latter case is denoted "catching up with the Joneses". Two specifications of habit formation are usually used in the literature. The first one (see Campbell and Cochrane [1999]) considers that the agent cares about the difference between his/her current consumption and a consumption standard. The second (see Abel [1990]) assumes that the agent cares about the ratio between these two quantities. One important difference between the two approaches is that the coefficient of risk aversion is time varying in the first case, while it remains constant in the second specification. This has strong consequences for the ability of the model to account for the predictability puzzle, as a time-varying coefficient is thought to be required to solve the puzzle. This therefore seems to preclude the use of a ratio specification to tackle the predictability of stock returns. One of the main contribution of this paper will be to show that, despite the constant risk aversion coefficient, habit formation in ratio can replicate the long horizon returns predictability. Hence, the model is by no means designed to solve neither the equity premium puzzle nor the risk free rate puzzle, since it is well known that time varying risk aversion is necessary to replicate the data. ${ }^{1}$ Our aim is rather to highlight the role of persistence generated by habits in accounting for the predictability puzzle, leaving the equity premium puzzle aside.

We develop a simple consumption based capital asset pricing model à la Lucas [1978]. We however depart from the standard setting in that we allow preferences to be non time separable. The model has the attractive feature of introducing tractable and parsimonious time non separability in a general equilibrium framework. More precisely, we consider that preferences are characterized by a "catching up with the Joneses" phenomenon. Preferences depend on lagged aggregate consumption. In a second step, we allow preferences to depend not only on lagged aggregate consumption but also on the whole history of aggregate consumption, therefore reinforcing both the time non-separability and persistence. We follow Abel [1990] and specify habit persistence in terms of ratio. This particular feature together with a CRRA utility function implies that preferences are homothetic with regard to consumption. As in Burnside [1998], we assume that endowments grow at an exogenous stochastic rate and we keep with the Gaussian assumption.

\footnotetext{
${ }^{1}$ Habit formation in ratio is known to fails to account for both puzzles. See Campbell et al. [1997] p. 328-329 and Campbell [2003].
} 
These features enable us to obtain a closed form solution to the asset pricing problem and give conditions that guarantee that the solution is bounded. This analytical treatment of the model enable us to provide with a more transparent understanding of the main mechanisms at work. We then investigate the dynamic properties of the model and its implications in terms of moment matching and predictability over long horizons. We find that, as expected, the time separable model fails to account for most of asset pricing properties. The "catching up with the Joneses" model enhances the properties of the CCAPM to match the stylized facts but its persistence properties are too weak to solve the predictability puzzle. In contrast, the model with habit stock is found to generate much stronger persistence, which enables it to solve, to a large extent, the predictability puzzle.

The remaining of the paper is organized as follows. Section 1 develops the model with catching up with the Joneses preferences. We derive the analytical form of the equilibrium solution and the conditions that guarantee the existence of bounded solutions, assuming that dividend growth is Gaussian and serially correlated. In section 2, we extend the model to a more general setting in which preferences depend on the whole history of the past aggregate consumptions. We provide again a closed form solution for price-dividend ratio and the conditions that guarantee bounded solutions. In section 3, we investigate the ability of the model to match a set of moments characterizing financial markets. In particular, we assess the ability of the model to account for the predictability puzzle. A last section offers some concluding remarks.

\section{Catching-up with the Joneses}

In this section, we develop a consumption based asset pricing model in which preferences exhibit a "Catching up with the Joneses" phenomenon. We provide the closed-form solution for the price-dividend ratio and conditions that guarantee the existence of a stationary bounded equilibrium.

\subsection{The Model}

We consider a pure exchange economy à la Lucas [1978]. The economy is populated by a single infinitely-lived representative agent. The agent has preferences over consumption, 
represented by the following intertemporal expected utility function

$$
\mathbb{E}_{t} \sum_{s=0}^{\infty} \beta^{s} u_{t+s}
$$

where $\beta>0$ is a constant discount factor, and $u_{t}$ denotes the instantaneous utility function, that will be defined later. Expectations are conditional on information available at the beginning of period $t$.

The agent enters period $t$ with a number of shares, $S_{t}$ - measured in terms of consumption goods - carried over the previous period as a means to transfer wealth intertemporally. Each share is valuated at price $P_{t}$. At the beginning of the period, she receives dividends, $D_{t} S_{t}$ where $D_{t}$ is the dividend per share. These revenues are then used to purchase consumption and new shares, $S_{t+1}$, at price $P_{t}$. The budget constraint therefore writes

$$
P_{t} S_{t+1}+C_{t} \leqslant\left(P_{t}+D_{t}\right) S_{t}
$$

Following Abel $[1990,1999]$, we assume that the instantaneous utility function, $u_{t}$, takes the form

$$
u_{t} \equiv u\left(C_{t}, V_{t}\right)= \begin{cases}\frac{\left(C_{t} / V_{t}\right)^{1-\theta}-1}{1-\theta} & \text { if } \theta \in \mathbb{R}_{+} \backslash\{1\} \\ \log \left(C_{t}\right)-\log \left(V_{t}\right) & \text { if } \theta=1\end{cases}
$$

where $\theta$ measures the degree of relative risk aversion and $V_{t}$ denotes the habit level.

We assume $V_{t}$ is a function of lagged aggregate consumption, $\bar{C}_{t-1}$, and is therefore external to the agent. This assumption amounts to assume that preferences are characterized by a "Catching up with the Joneses" phenomenon. ${ }^{2}$ More precisely, we assume that ${ }^{3}$

$$
V_{t}=\bar{C}_{t-1}^{\varphi}
$$

where $\varphi \geqslant 0$ rules the sensitivity of household's preferences to past aggregate consumption, $\bar{C}_{t-1}$, and therefore measures the degree of "Catching up with the Joneses". It is worth noting that habit persistence is specified in terms of the ratio of current consumption to a function of lagged consumption. We hereby follow Abel [1990] and depart from a strand of the literature which follows Campbell and Cochrane [1999] and specifies habit

\footnotetext{
${ }^{2}$ Note that had $V_{t}$ been a function of current aggregate consumption, we would have recovered Galí's [1989] "Keeping up with the Jones". As it will be clear later, in such a case the model admits that same analytical solution as in Burnside [1998].

${ }^{3}$ Note that this specification of the preference parameter can be understood as a particular case of Abel [1990] specification which is, in our notations, given by $V_{t}=\left[C_{t-1}^{D} \bar{C}_{t-1}^{1-D}\right]^{\gamma}$ with $0 \leqslant D \leqslant 1$ and $\gamma \geqslant 0$.
} 
persistence in terms of the difference between current and past aggregate consumption. This particular feature of the model will enable us to obtain a closed form solution to the asset pricing problem while keeping the main properties of habit persistence. Indeed, as shown by Burnside [1998], one of the keys to a closed form solution is that the marginal rate of substitution between consumption at two dates is an exponential function of the growth rate of consumption between these two dates. This is indeed the case with this particular form of catching up. Another implication of this specification is that, just alike the standard CRRA utility function, the individual risk aversion remains time-invariant and is unambiguously given by $\theta$.

Another attractive feature of this specification is that is nests several standard specifications. For instance, setting $\theta=1$ leads to the standard time separable case, as in this case the instantaneous utility function reduces to $\log \left(C_{t}\right)-\varphi \log \left(\bar{C}_{t-1}\right)$. As aggregate consumption, $\bar{C}_{t-1}$, is not internalized by the agents when taking their consumption decisions, the (maximized) utility function actually reduces to $\mathbb{E}_{t} \sum_{s=0}^{\infty} \beta^{s} \log \left(C_{t+s}\right)$. The intertemporal utility function is time separable and the solution for the price-dividend ratio is given by $P_{t} / D_{t}=\beta /(1-\beta)$.

Setting $\varphi=0$, we recover a standard time separable CRRA utility function of the form $\mathbb{E}_{t} \sum_{s=0}^{\infty} \beta^{s}\left(C_{t+s}^{1-\theta}-1\right) /(1-\theta)$. In such a case, Burnside [1998] showed that as long as dividend growth is log-normally distributed, the model admits a closed form solution. ${ }^{4}$

Setting $\varphi=1$ we retrieve Abel's [1990] relative consumption case (case B in Table 1, p.41) when shocks to endowments are iid. In this case, the household values increases in her individual consumption vis à vis lagged aggregate consumption. In equilibrium, $C_{t-1}=\bar{C}_{t-1}$ and it turns out that utility is a function of consumption growth.

At this stage, no further restriction will be placed on either $\beta, \theta$ or $\varphi$.

The household determines her contingent consumption $\left\{C_{t}\right\}_{t=0}^{\infty}$ and contingent asset holdings $\left\{S_{t+1}\right\}_{t=0}^{\infty}$ plans by maximizing (1) subject to the budget constraint (2), taking exogenous shocks distribution as given, and (3) and (4) given. Agents' consumption decisions are then governed by the following Euler equation

$$
P_{t} C_{t}^{-\theta} \bar{C}_{t-1}^{\varphi(\theta-1)}=\beta \mathbb{E}_{t}\left[\left(P_{t+1}+D_{t+1}\right) C_{t+1}^{-\theta} \bar{C}_{t}^{\varphi(\theta-1)}\right]
$$

\footnotetext{
${ }^{4}$ And therefore so does the "Keeping up with the Joneses" case.
} 
which may be rewritten as

$$
\frac{P_{t}}{D_{t}}=\mathbb{E}_{t}\left[\left(1+\frac{P_{t+1}}{D_{t+1}}\right) \times \mathscr{W}_{t+1} \times \Phi_{t+1}\right] \times \mathscr{C}_{t}
$$

where $\mathscr{W}_{t+1} \equiv D_{t+1} / D_{t}$ captures the wealth effect of dividend, $\Phi_{t+1} \equiv \beta\left[\left(C_{t+1} / C_{t}\right)^{-\theta}\right]$ is the standard stochastic discount factor arising in the time separable model. This Euler equation has an additional stochastic factor $\mathscr{C}_{t} \equiv\left(\bar{C}_{t} / \bar{C}_{t-1}\right)^{\varphi(\theta-1)}$ which measures the effect of "catching up with the Joneses". These two latter effects capture the intertemporal substitution motives in consumption decisions. Note that $\mathscr{C}_{t}$ is known with certainty in period $t$ as it only depends on current and past aggregate consumption. This new component distorts the standard intertemporal consumption decisions arising in a standard time separable model. Note that our specification of the utility function implies that $\varphi$ essentially governs the size of the catching up effect, while risk aversion, $\theta$, governs its direction. For instance, when risk aversion is high - $\theta>1$ - catching-up exerts a positive effect on the time separable intertemporal rate of substitution. Hence, in this case, for a given rate of consumption growth, catching up reduces the expected return.

Since we assumed the economy is populated by a single representative agent, we have $S_{t}=1$ and $C_{t}=\bar{C}_{t}=D_{t}$ in equilibrium. Hence, both the stochastic discount factor in the time separable model and the "catching up with the Joneses" term are functions of dividend growth $D_{t+1} / D_{t}$

$$
\Phi_{t+1} \equiv \beta\left[\left(D_{t+1} / D_{t}\right)^{-\theta}\right] \text { and } \quad \mathscr{C}_{t} \equiv\left(D_{t} / D_{t-1}\right)^{\varphi(\theta-1)}
$$

Any persistent increase in future dividends, $D_{t+1}$, leads to two main effects in the standard time separable model. First, a standard wealth effect, stemming from the increase in wealth it triggers $\left(\mathscr{W}_{t+1}\right)$, leads the household to consume more and purchase more assets. This puts upward pressure on asset prices. Second, there is an effect on the stochastic discount factor $\left(\Phi_{t+1}\right)$. Larger future dividends lead to greater future consumption and therefore lower future marginal utility of consumption. The household is willing to transfer $t+1$ consumption toward period $t$, which can be achieved by selling shares therefore putting downward pressure on prices. When $\theta>1$, the latter effect dominates and prices are a decreasing function of dividend. In the "catching up" model, a third effect, stemming from habit persistence $\left(\mathscr{C}_{t}\right)$, comes into play. Habit standards limit the willingness of the household to transfer consumption intertemporally. Indeed, when the household brings future consumption back to period $t$, she hereby raises the consumption standards for the next period. This raises future marginal utility of consumption and therefore plays 
against the stochastic discount factor effect. Henceforth, this limits the decrease in asset prices and can even reverse the effect when $\varphi$ is large enough.

Defining the price- dividend ratio as $v_{t}=P_{t} / D_{t}$, it is convenient to rewrite the Euler equation, evaluated at the equilibrium as

$$
v_{t}=\beta \mathbb{E}_{t}\left[\left(1+v_{t+1}\right)\left(\frac{D_{t+1}}{D_{t}}\right)^{1-\theta}\left(\frac{D_{t}}{D_{t-1}}\right)^{\varphi(\theta-1)}\right]
$$

\subsection{Solution and Existence}

In this section, we provide a closed form solution for the price-dividend ratio and give conditions that guarantee the existence of a stationary bounded equilibrium.

Note that up to now, no restrictions have been placed on the stochastic process governing dividends. Most of the literature attempting to obtain an analytical solution to the problem assumes that the rate of growth of dividends is an iid gaussian process (see Abel [1990,1999] among others). We depart from the iid case and follow Burnside [1998]. We assume that dividends grow at rate $\gamma_{t} \equiv \log \left(D_{t} / D_{t-1}\right)$, and that $\gamma_{t}$ follows an $\operatorname{AR}(1)$ process of the form

$$
\gamma_{t}=\rho \gamma_{t-1}+(1-\rho) \bar{\gamma}+\varepsilon_{t}
$$

where $\varepsilon_{t} \leadsto \mathscr{N}\left(0, \sigma^{2}\right)$ and $|\rho|<1$. Setting $\rho=0$, we retrieve the iid case. In the $\operatorname{AR}(1)$ case, the Euler equation rewrites

$$
v_{t}=\beta \mathbb{E}_{t}\left[\left(1+v_{t+1}\right) \exp \left((1-\theta) \gamma_{t+1}-\varphi(1-\theta) \gamma_{t}\right)\right]
$$

We can then establish the following proposition.

Proposition 1 The Solution to Equation (9) is given by

$$
v_{t}=\sum_{i=1}^{\infty} \beta^{i} \exp \left(a_{i}+b_{i}\left(\gamma_{t}-\bar{\gamma}\right)\right)
$$

where

$$
\begin{aligned}
& a_{i}=(1-\theta)(1-\varphi) \bar{\gamma} i+\left(\frac{1-\theta}{1-\rho}\right)^{2} \frac{\sigma^{2}}{2}\left[(1-\varphi)^{2} i-2 \frac{(1-\varphi)(\rho-\varphi)}{1-\rho}\left(1-\rho^{i}\right)+\frac{(\rho-\varphi)^{2}}{1-\rho^{2}}\left(1-\rho^{2 i}\right)\right] \\
& b_{i}=\frac{(1-\theta)(\rho-\varphi)}{1-\rho}\left(1-\rho^{i}\right)
\end{aligned}
$$


First of all it is worth noting that this pricing formula resembles that exhibited in Burnside [1998]. We actually recover Burnside's formulation by setting $\varphi=0$ - i.e imposing time separability in preferences. Second, when the rate of growth of endowments is iid over time $\left(\gamma_{t}=\bar{\gamma}+\varepsilon_{t}\right)$, and $\varphi$ is set to 1 , we recover the solution used by Abel [1990] to compute unconditional expected returns:

$$
z_{t}=\beta \exp \left((1-\theta)^{2} \frac{\sigma^{2}}{2}+(1-\theta)\left(\gamma_{t}-\bar{\gamma}\right)\right)
$$

In this latter case, the price-dividend ratio is an increasing (resp. decreasing) and convex function of the consumption growth if $\theta>1$ (resp. $\theta<1$ ). Things are more complicated when we consider the general model. Indeed, as shown in proposition 1 (see coefficient $b_{i}$ ), both the position of the curvature parameter, $\theta$, around 1 and the position of the persistence of dividend growth, $\rho$, around the parameter of habit persistence, $\varphi$, matter.

The behavior of an agent in face a positive shock on dividend growth essentially depends on the persistence of the process of endowments. This is illustrated in Figure 1 which reports the behavior of the price-dividend ratio as a function of the rate of growth of dividends for $\theta$ below and above 1 .

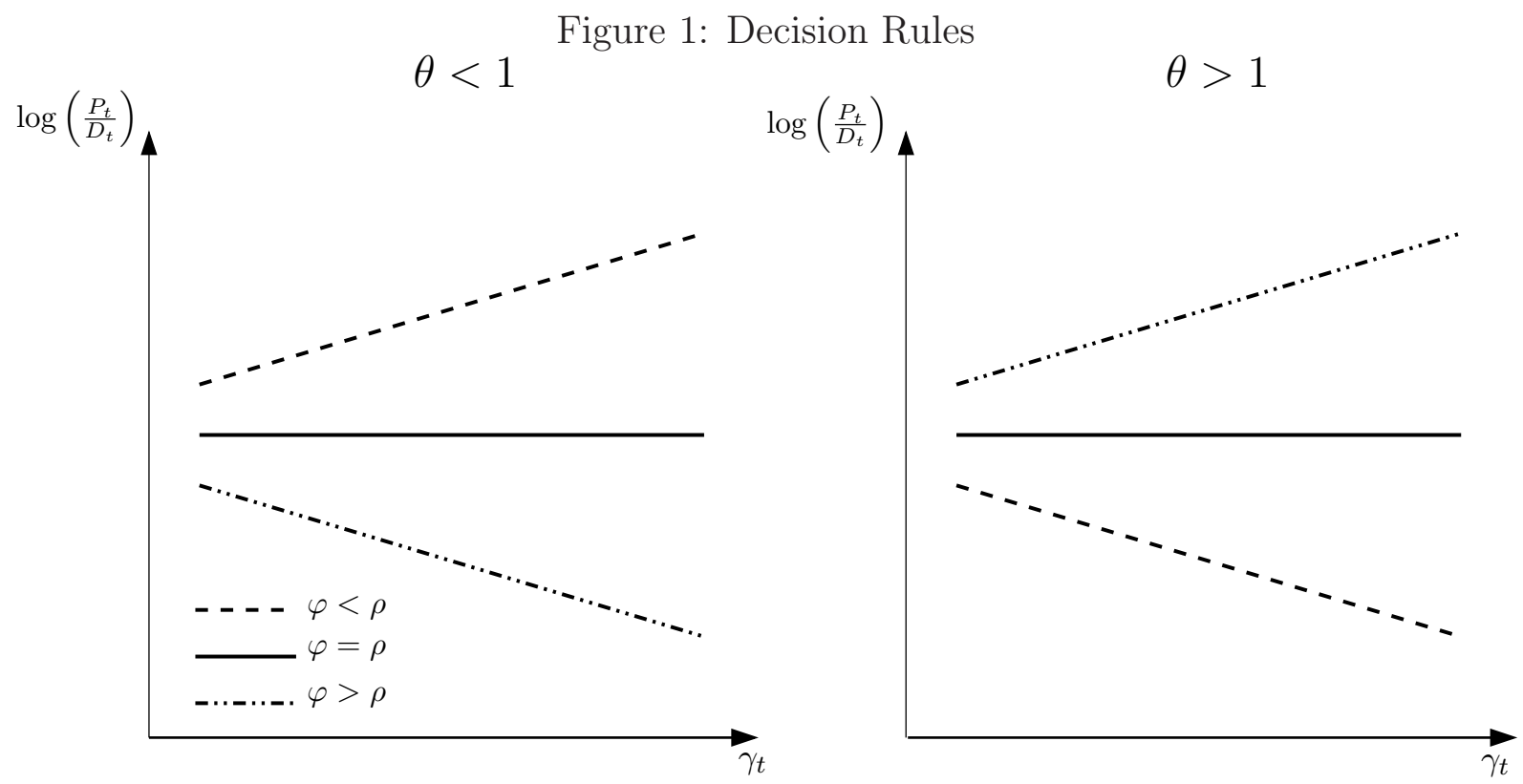

Let us consider the case $\theta>1$ (see right panel of Figure 1). As we established in the previous section, a shock on dividends exerts three effects: (i) a standard wealth effect, (ii) a stochastic discount factor effect and (iii) a habit persistence effect. The two latter effects play in opposite direction on intertemporal substitution. When $\varphi>\rho$, 
the stochastic discount factor effect is dominated by the force of habits, as the shock on dividend growth exhibits less persistence than habits. Therefore, the second and the third effects partially offset each other and the wealth effect plays a greater role. The pricedividend ratio increases. Conversely, when $\varphi<\rho$ habit persistence cannot counter the effects of expected stochastic discounting, and intertemporal substitution motives take the upper hand. The price-dividends ratio decreases. Note that in the limiting case where $\rho=\varphi$ (plain dark line in Figure 1) the persistence of dividend growth exactly offsets the effects of "catching up" and all three effects cancel out. Therefore, just alike the case of a logarithmic utility function, the price-dividend ratio is constant. The reasoning is reversed when $\theta<1$ (see left panel of Figure 1).

It is worth noting that Proposition 1 only establishes the existence of a solution, and does not guarantee that this solution is bounded. Indeed, the solution for the price-dividend ratio involves a series which may or may not converge. The next proposition reports conditions that that guarantee the existence of a stationary bounded equilibrium.

Proposition 2 The series in (10) converges if and only if

$$
r \equiv \beta\left[(1-\theta)(1-\varphi) \bar{\gamma}+\frac{\sigma^{2}}{2}\left(\frac{(1-\theta)(1-\varphi)}{1-\rho}\right)^{2}\right]<1
$$

As in Burnside [1998], this proposition shows that, given a 4 -uplet $(\theta, \varphi, \rho, \sigma), \beta<1$ is neither necessary nor sufficient to insure finite asset prices. In particular, the solution may converge even for $\beta>1$ when agents are highly risk adverse. Furthermore, the greater the "catching up", the easier it is for the series to converge. Conversely, $\beta$ should be lower as $\rho$ approaches unity.

Related to the convergence of the series is the convergence of the moments of the pricedividend ratio. The next proposition establishes a condition for the first two moments of the price-dividend ratio to converge.

Proposition 3 The average and autocovariances of the price-dividend ratio converge to a finite constant if and only if $r<1$.

Proposition 3 extends previous results obtained by Burnside [1998] to the case of "catching up with the Joneses". However, the literature has shown that this representation of pref- 
erences fails to account for the persistence of the price-dividend ratio and the dynamics of asset returns. In the next section we therefore enrich the dynamics of the model.

\section{Catching-up with the Joneses and Habit Stock}

In this section, we extend the previous framework to a more general habit formation process. In particular, we allow habits to react only gradually to changes in aggregate consumption. We provide the closed-form solution for the price-dividend ratio and conditions that guarantee the existence of a stationary bounded equilibrium.

\subsection{The Model}

We depart from the previous model in that preferences are affected by the entire history of aggregate consumption per capita rather that the lagged aggregate consumption (see e.g. Sundaresan [1989], Constantidines [1990], Heaton [1995] or Campbell and Cochrane [1999] among others). More precisely, the habit level, $V_{t}$, takes the form

$$
V_{t}=X_{t}^{\varphi}
$$

where $X_{t}$ is the consumption standard. We assume that the effect of aggregate consumption on the consumption standard vanishes over time at the constant rate $\delta \in(0,1)$. More precisely, the consumption standard, $X_{t}$, evolves according to

$$
X_{t+1}=\bar{C}_{t}^{\delta} X_{t}^{1-\delta}
$$

Note that this specification departs from the standard habit formation formula usually encountered in the literature. Nevertheless, in order to provide with some economic intuition, the evolution of habits (12) may be rewritten as

$$
x_{t} \equiv \log \left(X_{t}\right)=\delta \sum_{i=0}^{\infty}(1-\delta)^{i} \log \left(\bar{C}_{t-i-1}\right)
$$

The reference consumption index, $X_{t}$, can be viewed as a weighted geometric average of past realizations of aggregate consumption. Equation (13) shows that $(1-\delta)$ governs the rate at which the influence of past consumption vanishes over time, or, otherwise states $\delta$ governs the persistence of the state variable $X_{t}$. Note that in the special case of $\delta=1$, we recover the "Catching up with the Joneses" preferences specification studied in the 
previous section. Conversely, setting $\delta=0$, we retrieve the standard time separable utility function as habit stock does not respond to changes in consumption anymore.

The representative agent then determines her contingent consumption $\left\{C_{t}\right\}_{t=0}^{\infty}$ and contingent asset holdings $\left\{S_{t+1}\right\}_{t=0}^{\infty}$ plans by maximizing her intertemporal expected utility function (1) subject to the budget constraint (2) and taking the law of habit formation (12) as given.

Agent's consumption decisions are governed by the following Euler equation:

$$
P_{t} C_{t}^{-\theta} X_{t}^{-\varphi(1-\theta)}=\beta E_{t}\left(P_{t+1}+D_{t+1}\right) C_{t+1}^{-\theta} X_{t+1}^{-\varphi(1-\theta)}
$$

which may actually be rewritten in the form of equation (6) as

$$
\mathbb{E}_{t}\left[\frac{P_{t+1}+D_{t+1}}{P_{t}} \times \Phi_{t+1}\right] \times \mathscr{X}_{t+1}=1
$$

where $\Phi_{t+1}$ is the stochastic discount factor defined in section 1.1 and $\mathscr{X}_{t+1} \equiv\left(X_{t+1} / X_{t}\right)^{\varphi(\theta-1)}$ accounts for the effect of the persistent "catching up with the Joneses" phenomenon. Note that as in the previous model, the predetermined variable $\mathscr{X}_{t+1}$ distorts intertemporal consumption decisions in a standard time separable model.

\subsection{Solution and existence}

In equilibrium, we have $S_{t}=1$ and $\bar{C}_{t}=C_{t}=D_{t}$, implying that $X_{t+1}=D_{t}^{\delta} X_{t}^{1-\delta}$. As in the previous section, we assume that the growth rate of dividends follows an $\mathrm{AR}(1)$ process of the form (8). It is then convenient to rewrite equation (14) as

$$
y_{t}=\beta E_{t}\left[\exp \left((1-\theta)(1-\varphi) \gamma_{t+1}-\varphi(1-\theta) z_{t+1}\right)+\exp \left((1-\theta)(1-\varphi) \gamma_{t+1}\right) y_{t+1}\right]
$$

where $z_{t}=\log \left(X_{t} / D_{t}\right)$ denotes the $(\log )$ habit-dividend ratio and $y_{t}=v_{t} \exp \left(-\varphi(1-\theta) z_{t}\right)$. This forward looking equation admits the closed form solution reported in the next proposition.

Proposition 4 The equilibrium price-dividend ratio is given by:

$$
v_{t}=\sum_{i=1}^{\infty} \beta^{i} \exp \left(a_{i}+b_{i}\left(\gamma_{t}-\bar{\gamma}\right)+c_{i} z_{t}\right)
$$


where

$$
\begin{aligned}
& a_{i}=(1-\theta) \bar{\gamma}\left[(1-\varphi) i+\frac{\varphi}{\delta}\left(1-(1-\delta)^{i}\right)\right]+\frac{\mathscr{V}}{2} \\
& b_{i}=(1-\theta)\left[\frac{\rho(1-\varphi)}{1-\rho}\left(1-\rho^{i}\right)+\frac{\varphi \rho}{1-\delta-\rho}\left((1-\delta)^{i}-\rho^{i}\right)\right] \\
& c_{i}=\varphi(1-\theta)\left(1-(1-\delta)^{i}\right)
\end{aligned}
$$

and

$$
\begin{aligned}
\mathscr{V}= & (1-\theta)^{2} \sigma^{2}\left\{\left(\frac{1-\varphi}{1-\rho}\right)^{2}\left(i-2 \frac{\rho}{1-\rho}\left(1-\rho^{i}\right)+\frac{\rho^{2}}{1-\rho^{2}}\left(1-\rho^{2 i}\right)\right)\right. \\
& +2 \frac{\varphi(1-\varphi)}{(1-\rho)(1-\delta-\rho)}\left(\frac{(1-\delta)}{\delta}\left(1-(1-\delta)^{i}\right)-\frac{\rho}{1-\rho}\left(1-\rho^{i}\right)-\frac{\rho(1-\delta)}{1-\rho(1-\delta)}\left(1-(\rho(1-\delta))^{i}\right)\right. \\
& \left.+\frac{\rho^{2}}{1-\rho^{2}}\left(1-\rho^{2 i}\right)\right)+\frac{\varphi^{2}}{(1-\delta-\rho)^{2}}\left(\frac{(1-\delta)^{2}}{1-(1-\delta)^{2}}\left(1-(1-\delta)^{2 i}\right)-2 \frac{\rho(1-\delta)}{1-\rho(1-\delta)}\left(1-(\rho(1-\delta))^{i}\right)\right. \\
& \left.\left.+\frac{\rho^{2}}{1-\rho^{2}}\left(1-\rho^{2 i}\right)\right)\right\}
\end{aligned}
$$

This solution obviously nests the pricing formula obtained in the previous model. Indeed, setting $\delta=1$, we recover the solution reported in proposition 1. As shown in section 1.2, the form of the solution essentially depends on the position of the curvature parameter, $\theta$, around 1 and the position of the habit persistence parameter, $\varphi$, around the persistence of the shock, $\rho$. In the generalized model, things are more complicated as the position of the persistence of habits, $1-\delta$, around $\varphi$ and $\rho$ is also key to determine the form of the solution as reflected in the form of the coefficient $b_{i}$. Nevertheless, expression (17) illustrates two important properties of our model. First, the price-dividend ratio is function of two state variables: the growth rate of dividends $\gamma_{t}$ and the habit-dividend ratio $z_{t}$. This feature is of particular interest as the law of motion of $z_{t}$ is given by

$$
z_{t+1}=(1-\delta) z_{t}-\gamma_{t+1}
$$

Therefore, $z_{t}$ is highly serially correlated for low values of $\delta$, and the price-dividend ratio inherits part of this persistence. A second feature of this solution is that any change in the rate of growth of dividend exerts two effects on the price-dividend ratio. A first direct effect transits through its standard effect on the capital income of the household and is reflected in the term $b_{i}$. A second effect transits through its effect on the habit-dividend ratio. This second effect may be either negative or positive depending on the position of $\theta$ with regard to 1 and the form of $c_{i}$. This implies that there is room for pro- or 
counter-cyclical variations in the dividend-price ratio. This is critical for the analysis of predictability in stock returns as section 3.3 will make clear. Finally, note that as soon as $\delta<1$, the price-dividend ratio will be persistent even in the case when the rate of growth of dividends is iid $(\rho=0)$ (see the expression for $c_{i}$ ).

As the solution for the price-dividend ratio involves a series, the next proposition determines conditions that guarantee the existence of a stationary bounded equilibrium.

Proposition 5 The series in (17) converges if and only if

$$
r \equiv \beta \exp \left[(1-\theta)(1-\varphi) \bar{\gamma}+\frac{\sigma^{2}}{2}\left(\frac{(1-\theta)(1-\varphi)}{1-\rho}\right)^{2}\right]<1
$$

It is worth noting that the result reported in proposition 5 is the same as in proposition 2. Hence, the conditions for the existence of a stationary bounded equilibrium are not altered by this more general specification of habit formation. From a technical point of view, this result stems from the geometrical lag structure of habit stock, which implies strict homotheticity of the utility function with respect to habit. From an economic point of view this reflects that habit formation essentially affects the transition dynamics of the model while leaving unaffected the long run properties of the economy.

Just like in the previous model, it is possible to establish the convergence of the first two moments of the price-dividend ratio.

Proposition 6 The average and the autocovariances of the price-dividend ratio converge to a constant if and only if $r<1$.

Propositions 5 and 6 provide us with a set of restrictions on the deep and forcing parameters of the economy, which can be used to guarantee the relevance of our quantitative evaluation of the models.

\section{Quantitative Evaluation}

This section investigates the ability of the model to account for the high positive autocorrelation of the price-dividend ratio we usually find on aggregate data. We then gauge the ability of the model to account for predictability of stock returns. 


\subsection{Parametrization}

The model is parameterized on US postwar annual data running from 1947 to 1995. Data are borrowed from Campbell [1999]..$^{5}$ The values of the parameters are reported in Table 1.

Table 1: Calibration

\begin{tabular}{lrr}
\hline \hline Parameter & & Value \\
\hline \multicolumn{1}{c}{ Forcing Variable $\left(\gamma_{t}\right)$} & \\
\hline Mean of dividend growth & $\bar{\gamma}$ & 0.022 \\
Standard deviation of dividend growth & $\sigma^{2}$ & 0.122 \\
Persistent parameter of dividend process & $\rho$ & -0.219 \\
\hline \multicolumn{2}{c}{ Stochastic Discount Factor $\left(\Phi_{t+1}\right)$} \\
\hline Curvature $\quad \theta$ & 1.500 \\
Constant discount factor & $\beta$ & 0.950 \\
\hline \multicolumn{2}{c}{ Habit Formation $\left(\mathscr{C}_{t}, \mathscr{X}_{t+1}\right)$} & \\
\hline Habit persistence parameter & $\varphi$ & {$[0,1]$} \\
Depreciation rate of habits & $\delta$ & {$[0.05,1]$} \\
\hline \hline
\end{tabular}

The parameters characterizing the exogenous stochastic process for real dividend growth are obtained by fitting an $\mathrm{AR}(1)$ process to the data. ${ }^{6}$ The estimated value for the persistence parameter, $\rho$, is -0.219 , and the standard deviation of the innovations is 0.122 . The average annual rate of growth of dividend, $\bar{\gamma}$, is estimated to $2.23 \%$.

The two parameters defining the properties of the stochastic discount factor, $\beta$ and $\theta$, are set in reference to previous studies. The parameter of risk aversion, $\theta$, is set to 1.5. The household is assumed to discount the future with a psychological interest rate of $5 \%$ per year, implying $\beta=0.95$.

The parameters defining habit persistence remain to be set. The habit persistence parameter, $\varphi$, takes on values ranging from 0 to 1 . We first investigate the standard case of time separable utility function, which corresponds to $\varphi=0$. We also investigate Abel's [1990] case where $\varphi$ is set to 1 , implying that utility is determined in equilibrium by aggregate consumption growth. Likewise, we consider several situations regarding the value of the depreciation rate, $\delta$, of the consumption standard. We first set its value to 1 ,

\footnotetext{
${ }^{5}$ Data can be downloaded from http://kuznets.fas.harvard.edu/ campbell/data.html.

${ }^{6}$ Whenever nominal quantities have to be converted into real ones, we use the consumption deflator defined in Grossman and Shiller [1981].
} 
therefore focusing on the simple "catching up with the Joneses" model. We then explicitly consider the situation of a habit stock, by allowing $\delta$ to take on values below unity. In particular, we will set $\delta=0.05$, which implies that the effect of current consumption on the consumption standard vanishes at an annual rate of $5 \%$. We will also consider intermediate situations.

The model is simulated using the closed form solution. Since it involves an infinite series, we truncated the infinite sum at a long enough horizon (5000 periods) to guarantee that adding additional terms would not improve convergence. For each simulation, 1000 draws are generated.

\subsection{A preliminary investigation}

This section assesses the quantitative ability of the model to account for a set of standard unconditional moments characterizing the dynamics of the risk free rate, stock returns, excess returns and the price-dividend ratio. In order to provide with an understanding of the main results, we begin by reporting the impulse response analysis of the model in face a positive shock on dividend growth. Figure 2 reports the impulse response function (IRF) of aggregate consumption, habits, excess returns and the price-dividend ratio to a standard deviation shock on dividend growth. The upper panel reports IRFs when dividend growth is iid while the lower panel reports them imposing the estimated process. Three cases are under investigation: (i) the time separable utility function (TS), (ii) the "catching up with the Joneses" (CJ) and (iii) habit stock (HS).

Let us first consider the time separable case (TS). In order to provide a better understanding of the internal mechanisms of the model, it is useful to first investigate the iid case. In this situation, a one standard deviation positive shock on dividend growth translates in an increase in the permanent income of the agent. Therefore, the permanent income hypothesis underlying this model implies that consumption jumps to its new steady state value on impact. Since the utility function is time separable and dividend growth is iid, the discount factor $\Phi_{t+1}$ is left unaffected by the shock. Therefore, asset prices react one for one with dividends. The price/dividend ratio is left unaffected. Likewise, since the excess return is a function of the discount factor, the shock exerts no effect on its dynamics. As soon as the iid hypothesis is relaxed (see lower panel), stock returns and the price-dividend ratio do react. Indeed, when $\rho$ is set at its empirical value $(\rho=-0.219)$, a current increase in dividend growth is followed by a decrease in the next period. This 
Figure 2: Impulse response functions

(a) iid case $(\rho=0)$
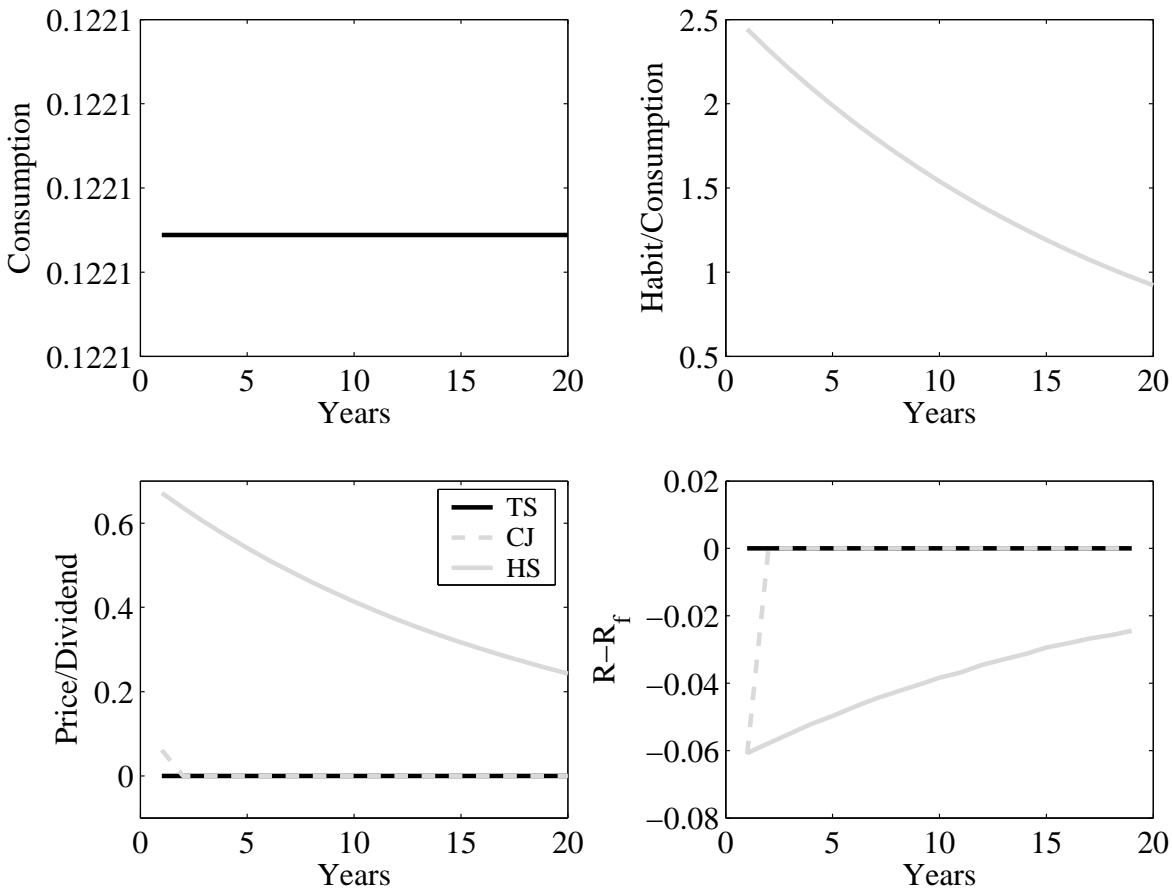

(b) estimated case $(\rho=-0.219)$
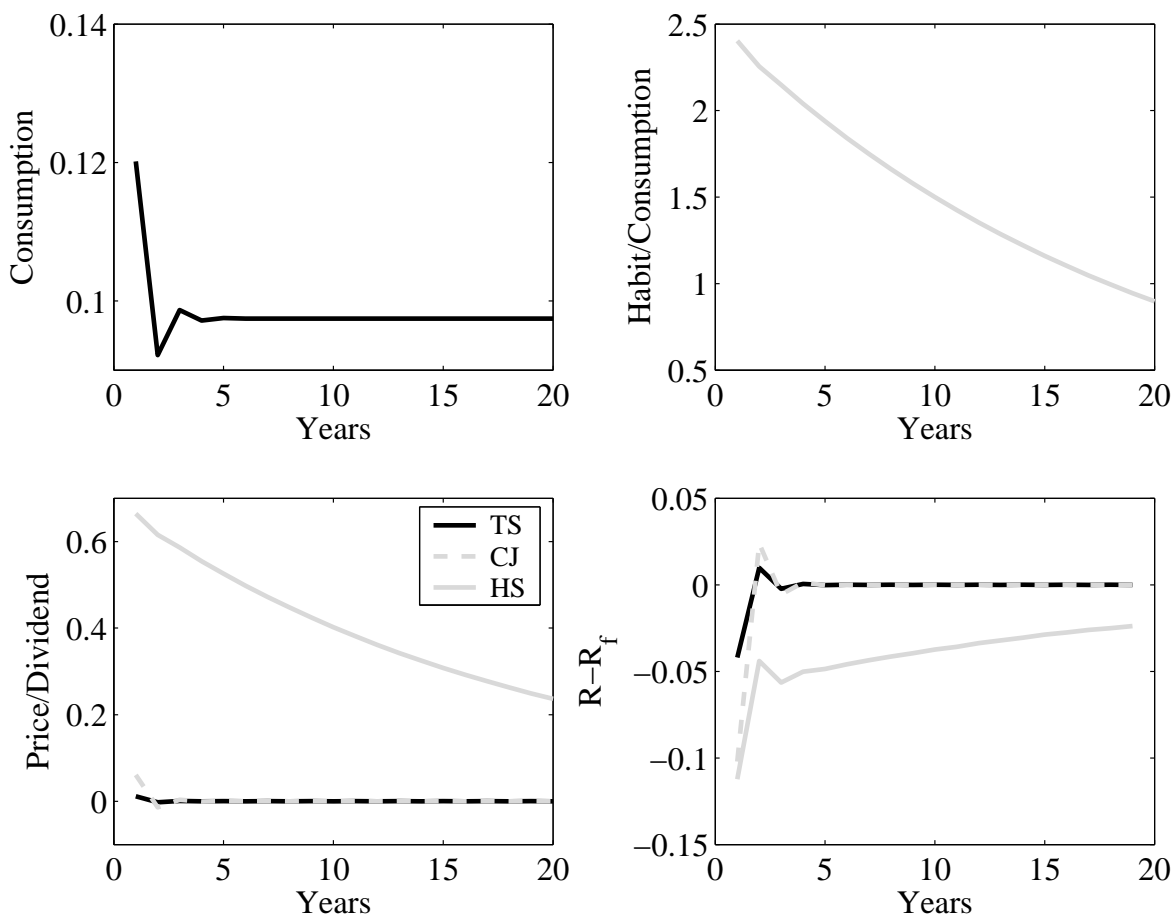

Note: TS: time separable preferences $(\varphi=0)$, CJ: Catching up with the Joneses preferences $(\varphi=1$ and $\delta=1)$, HS: habit stock specifications $(\varphi=1$ and $\delta=0.05)$ 
implies that the initial rise in consumption is followed by a relative drop. Hence, the marginal utility of future consumption increases and so does the discount factor. Therefore, as $\theta>1$, this effect takes the upper hand over the wealth effect and the price/dividend ratio raises. Note however that this effect reverses in the next period and so on. Therefore, given the value for $\rho$ the price-dividend ratio quickly goes back to its steady state level. Since the risk free rate is solely determined by the expected stochastic discount factor, it reacts to a larger extent than the risky rate which includes a wealth effect that counters the stochastic discount factor. Hence, the excess return drops on impact.

Bringing the "Catching up with the Joneses" phenomenon into the story barely affects the main conclusions. Indeed, the behavior of the price-dividend ratio and excess return differ very little on impact. Note that the consumption path is not affected by this assumption since it is exogenous. The only major difference arises on utility and asset prices which are affected in equilibrium by force of habit. Consider once again the iid case. The main mechanisms at work in the aftermaths of the shock on dividends are the same as in the TS version of the model. The only difference arises on impact because the habit term, $\mathscr{C}_{t}$, shift at the time of the shock and goes back to its steady state level in the next period. Therefore, the price dividend ratio jumps on impact and goes back to its steady state level in the second period. When the shock is not iid, the negative serial correlation of the shock shows up in the dynamics of asset prices and excess return, just as in the TS case.

In the habit stock version of the model asset prices and stock returns are largely affected. The sign of the effect is the same as in the previous versions but both its size and persistence is magnified. Indeed, as shown in Figure 2, the initial increase in dividends leads to a very persistent increase in habits even when dividend growth is iid. ${ }^{7}$ A direct implication of this is that the effects of habits $\left(\mathscr{X}_{t+1}\right)$ on the Euler equation is long lasting. This long lasting effect shows up in the evolution of the price-dividend ratio that essentially inherits the persistence of habits in the iid case and is much more responsive. Henceforth stock returns are also more persistent. Simulating the model using the estimated process essentially calls for similar comments to the two previous versions of the model.

The preceding discussion has important consequences for the quantitative properties of the model in terms of unconditional moments. Table 2 reports the mean and the standard deviation of the risk free rate, stock return, risk premium and the price-dividend ratio

\footnotetext{
${ }^{7}$ This persistence originates in the low depreciation rate of habits, $\delta=0.05$.
} 
for the data for the three versions of the model. As expected, the return on risky assets

Table 2: Unconditional Moments

\begin{tabular}{lcccccccc}
\hline \hline Variables & \multicolumn{2}{c}{ Data } & \multicolumn{2}{c}{ TS } & \multicolumn{2}{c}{ CJ } & \multicolumn{2}{c}{ HS } \\
& Mean & St Dev & Mean & St Dev & Mean & St Dev & Mean & St Dev \\
\hline$r_{f}$ & 1.45 & 2.63 & 6.82 & 4.08 & 5.71 & 10.30 & 5.75 & 4.56 \\
$r$ & 9.34 & 16.60 & 8.33 & 13.80 & 7.35 & 20.74 & 7.36 & 16.37 \\
$r-r_{f}$ & 7.89 & 16.08 & 1.51 & 17.87 & 1.63 & 30.74 & 1.60 & 20.55 \\
$p-d$ & 3.20 & 0.28 & 2.76 & 0.01 & 2.95 & 0.06 & 2.96 & 0.15 \\
\hline \hline
\end{tabular}

Note: TS: time separable preferences $(\varphi=0)$, CJ: Catching up with the Joneses preferences $(\varphi=1$ and $\delta=1)$, HS: habit stock specifications $(\varphi=1$ and $\delta=0.05)$

$(r)$ is larger return than the return on risk free assets $\left(r_{f}\right)$, implying the existence of an equity premium $\left(r-r_{f}\right)$ of about $7.9 \%$ per year. As well-known and expected (in the case of habit ratio), the model is not capable to deliver a satisfactory equity premium. For instance, the average equity premium is low in the time separable model, $1.5 \%$, and only rises to $1.6 \%$ for each version of the habit persistence model. It is however worth noting that the habit stock version of the model is able to match the volatility of risky returns. The habit stock model essentially outperforms the other models in terms of price dividend ratio. First of all, the model can deliver a large average of the price-dividend ratio $(2.96 \%)$ compared to the time separable model $(2.76 \%)$. Second, the model can account for the high volatility of the price dividend ratio. The time separable version of the model generates very low volatility $(0.01)$ as the IRF analysis has suggested. The catching up with the Joneses model delivers a slightly higher volatility (0.06). The habit stock model generates a volatility of about $0.15,15$ times that in the time separable model (see IRFs).

The major improvements are found in the ability of the model to match serial correlation of the price-dividend ratio (see Table 3). Historical data show large positive serial correlation. For instance, the first order autocorrelation is 0.88 in the data. The time separable model totally fails to account for such large and positive persistence, as the autocorrelation is negative at order $1(-0.23)$ and is essentially 0 at higher orders. This in fact reflects the persistence of the exogenous forcing variable as it possesses very weak internal propagation mechanism. The "catching up with the Joneses" model partially corrects this failure at the first order, as this autocorrelation is almost 0 . The habit stock model performs remarkably well at the first order as it generates the exact autocorrela- 
Table 3: Serial Correlation in Price-Dividend ratio

\begin{tabular}{lccccc}
\hline \hline Order & 1 & 2 & 3 & 5 & 7 \\
\hline Data & 0.88 & 0.76 & 0.71 & 0.40 & 0.05 \\
TS & -0.24 & 0.03 & -0.02 & -0.01 & -0.01 \\
CJ & -0.02 & -0.02 & -0.02 & -0.01 & -0.02 \\
HS & 0.88 & 0.85 & 0.80 & 0.72 & 0.65 \\
\hline \hline
\end{tabular}

Note: TS: time separable preferences $(\varphi=0)$, CJ: Catching up with the Joneses preferences $(\varphi=1$ and $\delta=1)$, HS: habit stock specifications $(\varphi=1$ and $\delta=0.05)$

tion. The model actually generates very high persistence, as it remains above 0.70 at the fifth order. This ability to generate high serial correlation in the price-dividend ratio is an important feature, as it reveals the ability of the model to account for the predictability of excess return. We now examine this issue.

\subsection{Long horizon predictability}

Over the last 20 years the empirical literature on asset prices has reported evidence suggesting that stock returns are indeed predictable. For instance, Campbell and Shiller [1987] or Fama and French [1988], among others, have shown that excess returns can be predicted by financial indicators including the price-dividend ratio or earnings to dividend ratios. The empirical evidence also shows that the predictive power of these financial indicators is greater when excess returns are measured over long horizons. This finding suggests that predictability is strongly related to the persistence problem. Therefore, it is not surprising to find that asset pricing models generating low persistence, such as the time separable CPAM model, cannot account for this stylized fact. In this section we investigate the ability of the model with habit stock to replicate predictability.

Table 4 is adapted from Fama and French [1988] and reports predictability tests on both historical and theoretical data. More precisely, we ran regressions of the (log) excess return on the (log) price-dividend ratio evaluated at several lags (up to 7 lags)

$$
\log \left(R_{t} / R_{f t}\right)=a_{k}+b_{k} \log \left(P_{t-k} / D_{t-k}\right)+u_{t}^{k}
$$

The table reports the coefficient, $b_{k}$, of the regression measuring the relationship between excess return and lagged price-dividend ratio and the $R^{2}$ of the regression measuring 
Table 4: Predictability

\begin{tabular}{|c|c|c|c|c|c|c|}
\hline \multicolumn{2}{|c|}{ Horizon (Years) } & 1 & 2 & 3 & 5 & 7 \\
\hline \multirow[t]{5}{*}{ Data } & $b$ & -0.25 & -0.42 & -0.54 & -0.92 & -1.31 \\
\hline & $R^{2}$ & 0.18 & 0.28 & 0.38 & 0.55 & 0.66 \\
\hline & & \multicolumn{5}{|c|}{ Time-separable } \\
\hline & $b$ & -4.63 & -3.82 & -4.30 & -4.53 & -5.00 \\
\hline & $R^{2}$ & 0.01 & 0.06 & 0.06 & 0.05 & 0.05 \\
\hline$\varphi$ & & \multicolumn{5}{|c|}{ Catching up with the Joneses } \\
\hline \multirow[t]{2}{*}{0.1} & $b$ & -1.51 & -1.99 & -2.53 & -3.25 & -4.32 \\
\hline & $R^{2}$ & 0.02 & 0.02 & 0.02 & 0.02 & 0.03 \\
\hline \multirow[t]{2}{*}{0.5} & $b$ & -1.13 & -1.25 & -1.38 & -1.54 & -1.80 \\
\hline & $R^{2}$ & 0.05 & 0.04 & 0.04 & 0.04 & 0.05 \\
\hline \multirow[t]{2}{*}{0.9} & $b$ & -1.09 & -1.16 & -1.25 & -1.35 & -1.52 \\
\hline & $R^{2}$ & 0.08 & 0.07 & 0.06 & 0.06 & 0.06 \\
\hline \multirow[t]{2}{*}{1} & $b$ & -1.09 & -1.15 & -1.23 & -1.33 & -1.48 \\
\hline & $R^{2}$ & 0.08 & 0.07 & 0.07 & 0.06 & 0.07 \\
\hline$(\varphi, \delta)$ & & \multicolumn{5}{|c|}{ Habit Stock } \\
\hline \multirow[t]{2}{*}{$(0.1,0.9)$} & $b$ & -3.67 & -3.05 & -3.42 & -3.59 & -3.95 \\
\hline & $R^{2}$ & 0.11 & 0.07 & 0.07 & 0.06 & 0.06 \\
\hline \multirow[t]{2}{*}{$(0.1,0.5)$} & $b$ & -3.59 & -3.09 & -3.52 & -3.80 & -4.26 \\
\hline & $R^{2}$ & 0.11 & 0.07 & 0.07 & 0.06 & 0.07 \\
\hline \multirow[t]{2}{*}{$(0.1,0.05)$} & $b$ & -3.13 & -3.01 & -3.61 & -4.30 & -5.08 \\
\hline & $R^{2}$ & 0.09 & 0.07 & 0.08 & 0.10 & 0.12 \\
\hline \multirow[t]{2}{*}{$(0.5,0.9)$} & $b$ & -2.39 & -2.01 & -2.23 & -2.32 & -2.52 \\
\hline & $R^{2}$ & 0.14 & 0.09 & 0.09 & 0.08 & 0.08 \\
\hline \multirow[t]{2}{*}{$(0.5,0.5)$} & $b$ & -1.80 & -1.77 & -2.04 & -2.26 & -2.56 \\
\hline & $R^{2}$ & 0.10 & 0.08 & 0.08 & 0.08 & 0.09 \\
\hline \multirow[t]{2}{*}{$(0.5,0.05)$} & $b$ & -0.99 & -1.17 & -1.51 & -1.99 & -2.48 \\
\hline & $R^{2}$ & 0.05 & 0.07 & 0.09 & 0.13 & 0.18 \\
\hline \multirow[t]{2}{*}{$(1,0.9)$} & $b$ & -1.95 & -1.66 & -1.82 & -1.88 & -2.02 \\
\hline & $R^{2}$ & 0.17 & 0.11 & 0.11 & 0.09 & 0.09 \\
\hline \multirow[t]{2}{*}{$(1,0.5)$} & $b$ & -1.29 & -1.28 & -1.48 & -1.65 & -1.87 \\
\hline & $R^{2}$ & 0.10 & 0.08 & 0.09 & 0.09 & 0.11 \\
\hline \multirow[t]{2}{*}{$(1,0.05)$} & $b$ & -0.46 & -0.60 & -0.79 & -1.09 & -1.37 \\
\hline & $R^{2}$ & 0.04 & 0.06 & 0.09 & 0.14 & 0.19 \\
\hline
\end{tabular}


the predictability of excess returns. The first line of the table reports empirical results obtained from historical data. Excess returns are negatively related to the price-dividend ratio whatever the horizon. The data also suggest that the larger the horizon, the larger the magnitude of this relationship. For instance, when the lagged price-dividend ratio is used to predict excess returns, the coefficient is -0.25 , while the coefficient is multiplied by around 5 and rises to -1.31 when 7 lags are considered. In other words, the price-dividend ratio accounts for greater volatility at longer horizons. A second worth noting fact is that the foreseeability of the price-dividend ratio is increasing with horizon as the $R^{2}$ of the regression increases with the lag horizon. For instance, the 1 year predictability regression indicates that the price-dividend ratio accounts for $18 \%$ of the overall volatility of the excess return. This share rises to $65 \%$ at the 7 years horizon.

The time separable model (TS) fails to account for predictability. The regression coefficient, $b$, remains almost constant with lags and the $R^{2}$ is essentially 0 whatever the horizon. This should come as no surprise as the impulse response analysis showed that while the price-dividend ratio responds very little and monotonically to a shock on dividend growth, excess returns are more responsive and display oscillations. A first implication of the little responsiveness of the price-dividend ratio is that the model largely overestimates the coefficient $b$ in the regression (around -5 ). A second implication is its tiny predictive power, as the $R^{2}$ is 0 .

As the IRF analysis has shown the "catching up with the Joneses" model possesses slightly stronger propagation mechanisms that may enhance its ability to account for predictability. In the third set of results of Table 4, we report predictability tests for this version of the model for several values of the habit persistence parameter $\varphi$. The first striking result is that allowing for "catching up" indeed improves the predictive power of the model, as the $b$ coefficient of the regression is much closer to that found in the data, at least at low horizon. For instance, when $\varphi=0.1$ - low habit persistence - the coefficient $b$ at horizon 1 drops to -1.51 , to be compared with -4.63 in the time separable model. But it should be noted that as the horizon increases $b$ increases dramatically in absolute value, reaching a value close to the TS model at the 7 years horizon. Hence, although the "catching up" model generates greater persistence, it is not enough to account for predictability for low values of $\varphi$. In other words, predictability comes with persistence. As the habit parameter increases the results get better. Setting $\varphi=1$ as in Abel [1990], the model generates a $b$ coefficient much closer to empirical evidence. For instance, for an horizon of 1 year, the model generates $b=-1.09$, which remains too large relative to the empirical evidence. As 
the horizon increases, $b$ comes closer to the data. For instance, at the 7 years horizon, the model leads to a value for $b$ of -1.48 when the data suggest a value of -1.31 . But it should be noted that the associated $R^{2}$ of the regression is, once again, essentially 0 . In other words, while adding "catching up with the Joneses" magnifies the persistence properties of the CCAPM, it is not sufficient to solve the predictability puzzle. In the last series

Figure 3: IRF and Predictability
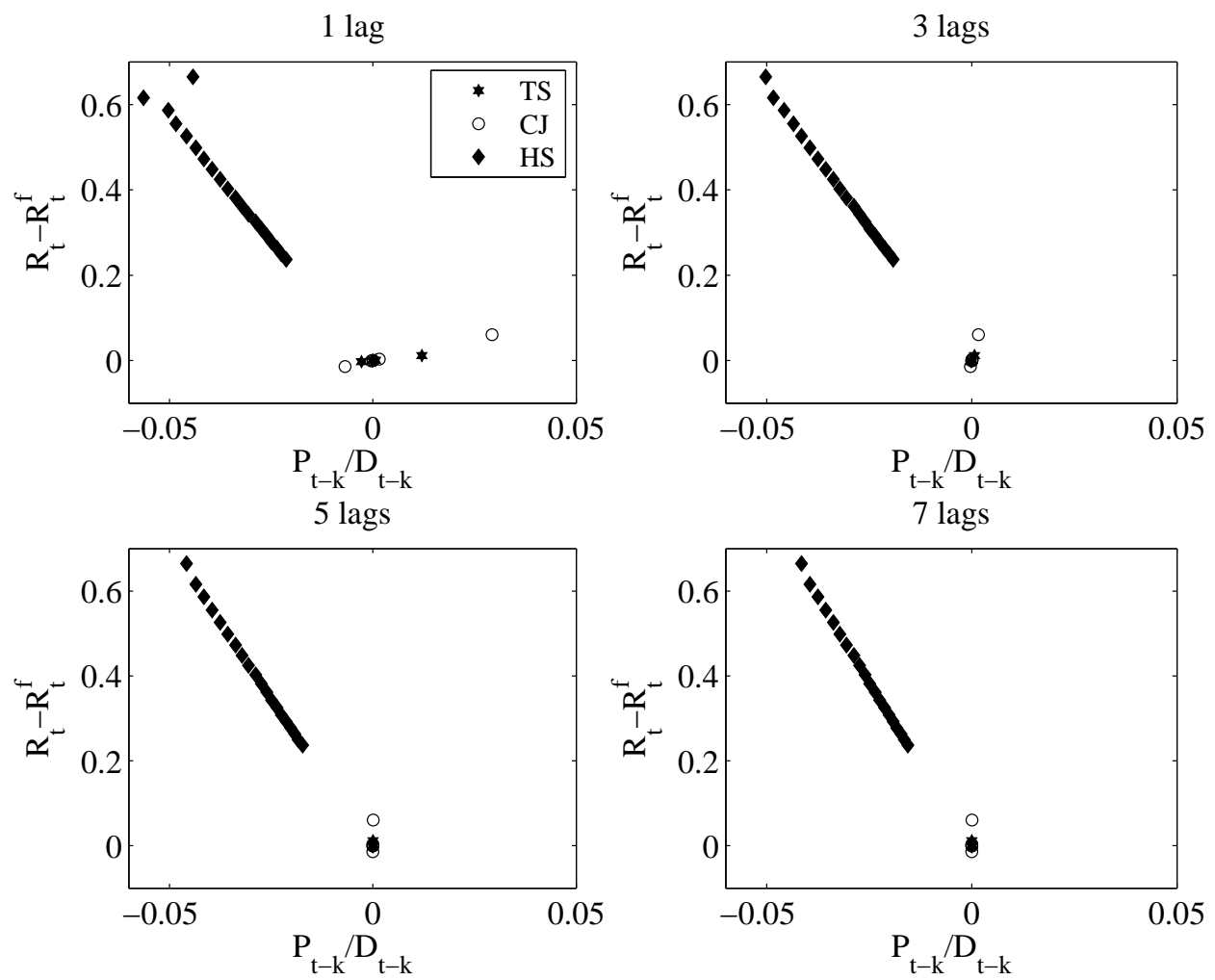

Note: TS: time separable preferences $(\varphi=0)$, CJ: Catching up with the Joneses preferences $(\varphi=1$ and $\delta=1)$, HS: habit stock specifications $(\varphi=1$ and $\delta=0.05)$

of results, we consider the habit stock version of the model and report results for several pairs of $(\varphi, \delta)$. These results clearly show that combining a "catching up" model with habit stock enhances the ability of the CCAPM to account for predictability, therefore highlighting the role of persistence in generating the results. For instance, setting $\varphi$ to a low value (0.1), a decrease in the depreciation rate of habits $(\delta)$ leads to a decrease in the magnitude of $b$ in absolute value and magnifies the gap between the $b$ at short and long horizons. Likewise it increases the $R^{2}$ of the regression at longer horizons. Setting $\varphi=1$ as in Abel [1990] and $\delta=0.05$, we almost recover the predictability found in the data. For example, $b$ at horizon 1 is -0.46 in the model to be compared with -0.25 in 
the data (recall that the corresponding value in the TS model was -4.63). At the 7 years horizon $b$ is -1.38 in the model and -1.31 in the data. The model therefore successfully matches the predictability results as far as $b$ is concerned. These results are not surprising and could have been inferred from the IRF analysis. For instance, in Figure 3, we plot the IRF of excess return versus that of lagged price/dividend ratio. Following an increase in dividends, the price dividend ratio rises while excess return drops on impact. The internal persistence generated by the model then makes the negative relationship persistent at various lags, therefore replicating predictability. Also note that neither the time separable nor the simple "catching up" model produce persistent enough negative relationship between the two prices. Results are less satisfactory although encouraging in terms of $R^{2}$. Indeed, the model can capture the evolution of $R^{2}$ with the horizon but its values remains much too low. For instance, the predictive power of the price/dividend ratio at the 7 years horizons amounts to $20 \%$ in the model when it reaches $66 \%$ in the data.

These predictability results establish that the habit stock model does a pretty good job in explaining stock returns. But they also highlight that this success is largely related to the stronger propagation mechanisms at work in this model — in particular in terms of persistence.

\section{Concluding Remarks}

This paper investigates the persistence and predictability properties of the standard consumption based asset pricing model à la Lucas [1978], when the model takes "catching up with the Joneses" and habit stock formation into account. Providing we keep with the assumption of first order Gaussian endowment growth and formulate habit formation in terms of ratio, we are able to provide a closed form solution for the price-dividend ratio. We also provide conditions that guarantee the existence of bounded solutions. We then assess the performance of the model in terms of moment matching. In particular, we study the ability of the model to generate persistence and explain the predictability puzzle. We then show that because it possesses strong persistence properties, the habit stock model can solve the puzzle. In contrast, the standard time separable model and the simple "catching up" model fail to account for predictability of asset prices. 


\section{References}

Abel, A., Asset Prices Under Habit Formation and Catching up with the Joneses, American Economic Review, Papers and Proceedings, 1990, 80 (2), 38-42.

— nomics, 1999, 43 (1), 3-33.

Boldrin, M., L.J. Christiano, and D.M. Fisher, Habit Persistence and Asset Returns in an Exchange Economy, Macroeconomic Dynamics, 1997, 1 (2), 312-332.

Burnside, C., Solving asset pricing with Gaussian shocks, Journal of Economic Dynamics and control, 1998, 22, 329-340.

Campbell, J., Asset Prices, Consumption, and the Business Cycle, in John B. Taylor and Michael Woodford, editors, Handbook of Macroeconomics, Vol. 1, Amsterdam: North-Holland, 1999, chapter 19, pp. 1231-1303.

— Consumption-Based Asset Pricing, in G. Constantinides, M. Harris, and R. Stulz, editors, Handbook of the Economics of Finance, Amsterdam: North-Holland, 2003. Forthcoming.

— _ A. Lo, and C. MacKinlay, The Econometrics of Financial Markets, Princeton (NJ): Princeton University Press, 1997.

Campbell, J.Y. and J.H. Cochrane, By Force of Habit: A Consumption-Based Explanation of Aggregate Stock Market Behavior, Journal of Political Economy, 1999, 10\%, $205-51$.

and R.J. Shiller, Cointegration and Tests of Present Value Models, Journal of Political Economy, 1987, 95, 1062-1087.

_ _ and _ The Dividend-Price Ratio and Expectations of Future Dividends and Discount Factors, Review of Financial Studies, 1988, 1, 195-227.

Chan, Y.L. and L. Kogan, Heterogeneous Preferences and the Dynamics of Asset Prices, Technical Report 8607, NBER 2001.

Cochrane, J.H., Where is the Market Going? Uncertain Facts and Novel Theories, Economic Perspectives, Federal Reserve Bank of Chicago, 1997, 11, 1-37. 
_ _ Asset Pricing, Princeton (NJ): Princeton University Press, 2001.

Constantidines, G.M., Habit Formation: A Resolution of the Equity Premium Puzzle, Journal of Political Economy, 1990, 98 (3), 519-543.

Fama, E.F. and K.R. French, Dividend Yields and Expected Stock Returns, Journal of Financial Economics, 1988, 22 (1), 3-25.

and __ B Business Conditions and Expected Returns on Stocks and Bonds, Journal of Financial Economics, 1989, 25 (1), 23-49.

Galí, J., Keeping Up with the Joneses: Consumption Externalities, Portfolio Choice and Asset Prices, Journal of Money, Credit, and Banking, 1994, pp. 1-8.

Grossman, S. and R. Shiller, The Determinant of the Variability of Stock Market Prices, American Economic Review, 1981, 71, 222-227.

Heaton, J., An Empirical Investigation of Asset Pricing with Temporally Dependent Preference Specifications, Econometrica, 1995, 63 (3), 681-717.

Hodrick, R., Dividend Yields and Expected Stock Returns: Alternative Procedures for Inference and Measurement, Review of Financial Studies, 1992, 5 (3), 357-386.

Lamont, O., Earnings and Expected Returns, Journal of Finance, 1998, 53, 1563-1587.

Lettau, M. and S. Ludvigson, Consumption, Aggregate Wealth, and Expected Stock Returns, Journal of Finance, 2001, 56 (3), 815-49.

Lucas, R., Asset Prices in an Exchange Economy, Econometrica, 1978, 46 (6), 1439-45.

Menzly, L., T. Santos, and P. Veronesi, Understanding Predictability, Journal of Political Economy, 2004, 112 (1), 1-47.

Poterba, J. and L.H. Summers, Mean Reversion in Stock Prices, Journal of Financial Economics, 1988, 22 (1), 27-59.

Sundaresan, S.M., Intertemporally Dependent Preferences and the Volatility of Consumption and Wealth, The Review of Financial Studies, 1989, 2 (1), 73-89. 


\section{A Proof of Propositions}

Proposition 1: See proof of Proposition 4

Proposition 2: See proof of Proposition 5

Proposition 3: See proof of Proposition 6

Proposition 4: First of all note that setting $\delta=1$ in this proof, we obtain a proof for Proposition 1. Let us denote $v_{t}=P_{t} / D_{t}$ the price-dividend ratio, and $z_{t}=\log \left(X_{t} / D_{t}\right)$ the habit to dividend ratio. Finally, letting $y_{t}=v_{t} \exp \left(-\varphi(1-\theta) z_{t}\right)$, the agent's Euler equation rewrites

$$
y_{t}=\beta E_{t}\left[\exp \left((1-\theta)(1-\varphi) \gamma_{t+1}-\varphi(1-\theta) z_{t+1}\right)+\exp \left((1-\theta)(1-\varphi) \gamma_{t+1}\right) y_{t+1}\right]
$$

Iterating forward, and imposing the transversality condition, a solution to this forward looking stochastic difference equation is given by

$$
y_{t}=E_{t} \sum_{i=1}^{\infty} \beta^{i} \exp \left((1-\theta)(1-\varphi) \sum_{j=1}^{i} \gamma_{t+j}-\varphi(1-\theta) z_{t+i}\right)
$$

Note that, the definition of $z_{t}$ and the law of motion of habits imply that $z_{t}$ evolves as

$$
z_{t+1}=(1-\delta) z_{t}-\gamma_{t+1}
$$

which implies that

$$
z_{t+i}=(1-\delta)^{i} z_{t}-\sum_{j=0}^{i-1}(1-\delta)^{j} \gamma_{t+i-j}
$$

Plugging the latter result in (19), we get

$$
y_{t}=E_{t} \sum_{i=1}^{\infty} \beta^{i} \exp \left((1-\theta) \sum_{j=1}^{i}\left((1-\varphi)+\varphi(1-\delta)^{i-j}\right) \gamma_{t+j}-\varphi(1-\theta)(1-\delta)^{i} z_{t}\right)
$$

Let us focus on the particular component of the solution

$$
\mathscr{G} \equiv E_{t} \exp \left((1-\theta) \sum_{j=1}^{i}\left((1-\varphi)+\varphi(1-\delta)^{i-j}\right) \gamma_{t+j}\right)
$$

Since we assumed that dividend growth is normally distributed, making use of standard results on lognormal distributions, we have that

$$
\mathscr{G}=\exp \left(\mathscr{E}+\frac{\mathscr{V}}{2}\right)
$$

where

$$
\mathscr{E}=E_{t}\left((1-\theta) \sum_{j=1}^{i}\left((1-\varphi)+\varphi(1-\delta)^{i-j}\right) \gamma_{t+j}\right)
$$

and

$$
\mathscr{V}=\operatorname{Var}_{t}\left((1-\theta) \sum_{j=1}^{i}\left((1-\varphi)+\varphi(1-\delta)^{i-j}\right) \gamma_{t+j}\right)
$$


Since $\gamma_{t}$ follows an $\mathrm{AR}(1)$ process, we have

$$
\gamma_{t+j}=\bar{\gamma}+\rho^{j}\left(\gamma_{t}-\bar{\gamma}\right)+\sum_{k=0}^{j-1} \rho^{k} \varepsilon_{t+j-k}
$$

such that

$$
\begin{aligned}
\mathscr{E} & =E_{t}\left[(1-\theta) \sum_{j=1}^{i}\left((1-\varphi)+\varphi(1-\delta)^{i-j}\right)\left(\bar{\gamma}+\rho^{j}\left(\gamma_{t}-\bar{\gamma}\right)+\sum_{k=0}^{j-1} \rho^{k} \varepsilon_{t+j-k}\right)\right] \\
& =\left[(1-\theta) \sum_{j=1}^{i}\left((1-\varphi)+\varphi(1-\delta)^{i-j}\right)\left(\bar{\gamma}+\rho^{j}\left(\gamma_{t}-\bar{\gamma}\right)\right)\right] \\
& =(1-\theta)(1-\varphi) \sum_{j=1}^{i}\left(\bar{\gamma}+\rho^{j}\left(\gamma_{t}-\bar{\gamma}\right)\right)+(1-\theta) \varphi \sum_{j=1}^{i}(1-\delta)^{i-j}\left(\bar{\gamma}+\rho^{j}\left(\gamma_{t}-\bar{\gamma}\right)\right) \\
& =(1-\theta) \bar{\gamma}\left[(1-\varphi) i+\frac{\varphi}{\delta}\left(1-(1-\delta)^{i}\right)\right]+(1-\theta)\left[\frac{\rho(1-\varphi)}{1-\rho}\left(1-\rho^{i}\right)+\frac{\varphi \rho}{1-\delta-\rho}\left((1-\delta)^{i}-\rho^{i}\right)\right]\left(\gamma_{t}-\bar{\gamma}\right)
\end{aligned}
$$

The calculation of the conditional variance is a bit more tedious.

$$
\mathscr{V}=\operatorname{Var}_{t}\left[(1-\theta) \sum_{j=1}^{i}\left(1-\varphi+\varphi(1-\delta)^{i-j}\right) \sum_{k=0}^{j-1} \rho^{k} \varepsilon_{t+j-k}\right]
$$

which after some accounting rewrites as

$$
\begin{aligned}
= & \operatorname{Var}_{t}\left[(1-\theta) \sum_{j=0}^{i-1}\left(\frac{1-\varphi}{1-\rho}\left(1-\rho^{i-j}\right)+\frac{\varphi}{1-\delta-\rho}\left((1-\delta)^{i-j}-\rho^{i-j}\right)\right) \varepsilon_{t+j+1}\right] \\
= & (1-\theta)^{2} \sigma^{2} \sum_{j=0}^{i-1}\left(\frac{1-\varphi}{1-\rho}\left(1-\rho^{i-j}\right)+\frac{\varphi}{1-\delta-\rho}\left((1-\delta)^{i-j}-\rho^{i-j}\right)\right)^{2} \\
= & (1-\theta)^{2} \sigma^{2}\left[\left(\frac{1-\varphi}{1-\rho}\right)^{2} \sum_{k=1}^{i}\left(1-\rho^{k}\right)^{2}+2 \frac{\varphi(1-\delta)}{(1-\rho)(1-\delta-\rho)} \sum_{k=1}^{i}\left(1-\rho^{k}\right)\left((1-\delta)^{k}-\rho^{k}\right)\right. \\
& \left.+\left(\frac{\varphi}{1-\delta-\rho}\right)^{2} \sum_{k=1}^{i}\left((1-\delta)^{k}-\rho^{k}\right)^{2}\right]
\end{aligned}
$$

Calculating all the infinite series, we end-up with

$$
\begin{aligned}
\mathscr{V}= & (1-\theta)^{2} \sigma^{2}\left\{\left(\frac{1-\varphi}{1-\rho}\right)^{2}\left(i-2 \frac{\rho}{1-\rho}\left(1-\rho^{i}\right)+\frac{\rho^{2}}{1-\rho^{2}}\left(1-\rho^{2 i}\right)\right)\right. \\
& +2 \frac{\varphi(1-\varphi)}{(1-\rho)(1-\delta-\rho)}\left(\frac{(1-\delta)}{\delta}\left(1-(1-\delta)^{i}\right)-\frac{\rho}{1-\rho}\left(1-\rho^{i}\right)-\frac{\rho(1-\delta)}{1-\rho(1-\delta)}\left(1-(\rho(1-\delta))^{i}\right)\right. \\
& \left.+\frac{\rho^{2}}{1-\rho^{2}}\left(1-\rho^{2 i}\right)\right)+\frac{\varphi^{2}}{(1-\delta-\rho)^{2}}\left(\frac{(1-\delta)^{2}}{1-(1-\delta)^{2}}\left(1-(1-\delta)^{2 i}\right)-2 \frac{\rho(1-\delta)}{1-\rho(1-\delta)}\left(1-(\rho(1-\delta))^{i}\right)\right. \\
& \left.\left.+\frac{\rho^{2}}{1-\rho^{2}}\left(1-\rho^{2 i}\right)\right)\right\}
\end{aligned}
$$

Therefore, the solution is given by

$$
y_{t}=\sum_{i=1}^{\infty} \beta^{i} \exp \left(a_{i}+b_{i}\left(\gamma_{t}-\bar{\gamma}\right)+\widetilde{c}_{i} z_{t}\right)
$$


where

$$
\begin{aligned}
a_{i} & =(1-\theta) \bar{\gamma}\left[(1-\varphi) i+\frac{\varphi}{\delta}\left(1-(1-\delta)^{i}\right)\right]+\frac{\mathscr{V}}{2} \\
b_{i} & =(1-\theta)\left[\frac{\rho(1-\varphi)}{1-\rho}\left(1-\rho^{i}\right)+\frac{\varphi \rho}{1-\delta-\rho}\left((1-\delta)^{i}-\rho^{i}\right)\right] \\
\widetilde{c}_{i} & =-\varphi(1-\theta)(1-\delta)^{i}
\end{aligned}
$$

recall that $y_{t}=v_{t} \exp \left(-\varphi(1-\theta) z_{t}\right)$, such that the price-dividend ratio is finally given by

$$
v_{t}=\exp \left(\varphi(1-\theta) z_{t}\right) \sum_{i=1}^{\infty} \beta^{i} \exp \left(a_{i}+b_{i}\left(\gamma_{t}-\bar{\gamma}\right)+\tilde{c}_{i} z_{t}\right)
$$

or

$$
v_{t}=\sum_{i=1}^{\infty} \beta^{i} \exp \left(a_{i}+b_{i}\left(\gamma_{t}-\bar{\gamma}\right)+c_{i} z_{t}\right)
$$

where $c_{i}=\varphi(1-\theta)\left(1-(1-\delta)^{i}\right)$.

Proposition 5: First of all note that setting $\delta=1$ in this proof, we obtain a proof for Proposition 2. Let us define

$$
w_{i}=\beta^{i} \exp \left(a_{i}+b_{i}\left(\gamma_{t}-\bar{\gamma}\right)+c_{i} z_{t}\right)
$$

where $a_{i}, b_{i}$ and $c_{i}$ are obtained from the previous proposition. Then, the price-dividend ratio rewrites

$$
v_{t}=\sum_{i=1}^{\infty} w_{i}
$$

It follows that

$$
\left|\frac{w_{i+1}}{w_{i}}\right|=\beta \exp \left(\Delta a_{i+1}+\Delta b_{i+1}\left(\gamma_{t}-\bar{\gamma}\right)+\Delta c_{i+1} z_{t}\right)
$$

where

$$
\begin{aligned}
\Delta a_{i+1}= & (1-\theta) \bar{\gamma}\left[(1-\varphi)+\varphi(1-\delta)^{i}\right]+(1-\theta)^{2} \frac{\sigma^{2}}{2}\left\{\left(\frac{1-\varphi}{1-\rho}\right)^{2}\left(1-2 \rho^{i+1}+\rho^{2(i+1)}\right)\right) \\
& +2 \frac{\varphi(1-\varphi)}{(1-\rho)(1-\delta-\rho)}\left((1-\delta)^{i+1}-\rho^{i+1}-(\rho(1-\delta))^{i+1}+\rho^{2(i+1)}\right) \\
& \left.+\frac{\varphi^{2}}{(1-\delta-\rho)^{2}}\left((1-\delta)^{2(i+1)}-2(\rho(1-\delta))^{i+1}+\rho^{2(i+1)}\right)\right\} \\
\Delta b_{i+1}= & (1-\theta)\left[(1-\varphi) \rho^{i+1}-\frac{\varphi \rho}{1-\delta-\rho}\left((1-\rho) \rho^{i}-\delta(1-\delta)^{i}\right)\right] \\
\Delta c_{i+1}= & \varphi(1-\theta) \delta(1-\delta)^{i}
\end{aligned}
$$

Also note that provided $|\rho|<1$ and $\delta \in(0,1)$, we have

$$
\begin{aligned}
& \lim _{i \rightarrow \infty} \Delta a_{i+1}=(1-\theta) \bar{\gamma}(1-\varphi)+(1-\theta)^{2} \frac{\sigma^{2}}{2}\left(\frac{1-\varphi}{1-\rho}\right)^{2} \\
& \lim _{i \rightarrow \infty} \Delta b_{i+1}\left(\gamma_{t}-\bar{\gamma}\right)=0 \\
& \lim _{i \rightarrow \infty} \Delta c_{i+1} z_{t}=0
\end{aligned}
$$

Therefore

$$
\lim _{i \rightarrow \infty}\left|\frac{w_{i+1}}{w_{i}}\right|=r \equiv \beta \exp \left((1-\theta) \bar{\gamma}(1-\varphi)+(1-\theta)^{2} \frac{\sigma^{2}}{2}\left(\frac{1-\varphi}{1-\rho}\right)^{2}\right)
$$

Using the ratio test, we now face three situations: 
i) When $r<1$, then $\lim _{i \rightarrow \infty}\left|\frac{w_{i+1}}{w_{i}}\right|<1$ and the ratio test implies that $\sum_{i=1}^{\infty} w_{i}$ converges.

ii) When $r>1$, the ratio test implies that $\sum_{i=1}^{\infty} w_{i}$ diverges.

iii) When $r=1$, the ratio test is inconclusive. But, if $r=1$, we know that

$$
\exp \left((1-\theta)(1-\varphi) \bar{\gamma}+\left(\frac{(1-\theta)(1-\varphi)}{1-\rho}\right)^{2} \frac{\sigma^{2}}{2}\right)=\frac{1}{\beta}
$$

and the parameter $a_{i}$ rewrites

$$
\begin{aligned}
a_{i}= & \left((1-\theta)(1-\varphi) \bar{\gamma}+\left(\frac{(1-\theta)(1-\varphi)}{1-\rho}\right)^{2} \frac{\sigma^{2}}{2}\right) i \\
& +\left(\frac{1-\theta}{1-\rho}\right)^{2} \frac{\sigma^{2}}{2}\left[\frac{(\rho-\varphi)^{2}}{1-\rho^{2}}\left(1-\rho^{2 i}\right)-2 \frac{(1-\varphi)(\rho-\varphi)}{1-\rho}\left(1-\rho^{i}\right)\right] \\
= & -\log (\beta) i+\left(\frac{1-\theta}{1-\rho}\right)^{2} \frac{\sigma^{2}}{2}\left[\frac{(\rho-\varphi)^{2}}{1-\rho^{2}}\left(1-\rho^{2 i}\right)-2 \frac{(1-\varphi)(\rho-\varphi)}{1-\rho}\left(1-\rho^{i}\right)\right]
\end{aligned}
$$

After replacement in $w_{i}$, we get:

$$
w_{i}=\exp \left(\tilde{a}_{i}+b_{i}\left(\gamma_{t}-\bar{\gamma}\right)+c_{i} z_{t}\right)
$$

where

$$
\widetilde{a}_{i}=\left(\frac{1-\theta}{1-\rho}\right)^{2} \frac{\sigma^{2}}{2}\left[\frac{(\rho-\varphi)^{2}}{1-\rho^{2}}\left(1-\rho^{2 i}\right)-2 \frac{(1-\varphi)(\rho-\varphi)}{1-\rho}\left(1-\rho^{i}\right)\right]
$$
Since $\lim _{i \rightarrow \infty}\left|\widetilde{a}_{i}\right|=\left|\left(\frac{1-\theta}{1-\rho}\right)^{2} \frac{\sigma^{2}}{2}\left[\frac{(\rho-\varphi)^{2}}{1-\rho^{2}}-2 \frac{(1-\varphi)(\rho-\varphi)}{1-\rho}\right]\right|>0$, then the series $v_{t}=\sum_{i=1}^{\infty} w_{i}$ di-
verges.

Therefore, $r<1$ is the only situation where a stationary bounded equilibrium exists.

Proposition 6: First of all note that setting $\delta=1$ in this proof, we obtain a proof for Proposition 3 . We first deal with the average of the price/dividend ratio. We want to compute

$$
\mathbb{E}\left(v_{t}\right)=\mathbb{E}\left(\sum_{i=1}^{\infty} \beta^{i} \exp \left(a_{i}+b_{i}\left(\gamma_{t}-\bar{\gamma}\right)+c_{i} z_{t}\right)=\sum_{i=1}^{\infty} \beta^{i} E\left(\exp \left(a_{i}+b_{i}\left(\gamma_{t}-\bar{\gamma}\right)+c_{i} z_{t}\right)\right.\right.
$$

By the $\log$-normality of $\gamma_{t}$, we know that

$$
\mathbb{E}\left(\exp \left(a_{i}+b_{i}\left(\gamma_{t}-\bar{\gamma}\right)+c_{i} z_{t}\right)=\exp \left(\mathscr{E}_{i}+\frac{\mathscr{V}_{i}}{2}\right)\right.
$$

where

$$
\mathscr{E}_{i}=E\left(a_{i}+b_{i}\left(\gamma_{t}-\bar{\gamma}\right)+c_{i} z_{t}\right)=a_{i}+c_{i} E\left(z_{t}\right)
$$

and

$$
\mathscr{V}_{i}=\operatorname{Var}\left(a_{i}+b_{i}\left(\gamma_{t}-\bar{\gamma}\right)+c_{i} z_{t}\right)=b_{i}^{2} \frac{\sigma^{2}}{1-\rho^{2}}+c_{i}^{2} \operatorname{Var}\left(z_{t}\right)+2 c_{i} b_{i} \operatorname{Cov}\left(z_{t}, \gamma_{t}\right)
$$

Recall that $z_{t}=(1-\delta) z_{t-1}-\gamma_{t}$, therefore

$$
E\left(z_{t}\right)=-\frac{\bar{\gamma}}{\delta}
$$


and

$$
\operatorname{Cov}\left(z_{t}, \gamma_{t}\right)=\operatorname{Cov}\left((1-\delta) z_{t-1}-\gamma_{t}, \gamma_{t}\right)=(1-\delta) \rho \operatorname{Cov}\left(z_{t-1}, \gamma_{t-1}\right)-\operatorname{Var}\left(\gamma_{t}\right)
$$

Hence

Furthermore, we know that

$$
\operatorname{Cov}\left(z_{t}, \gamma_{t}\right)=-\frac{\sigma^{2}}{(1-\rho(1-\delta))\left(1-\rho^{2}\right)}
$$

$$
\begin{aligned}
\operatorname{Var}\left(z_{t}\right) & =(1-\delta)^{2} \operatorname{Var}\left(z_{t}\right)+\operatorname{Var}\left(\gamma_{t}\right)-2(1-\delta) \operatorname{Cov}\left(z_{t-1}, \gamma_{t}\right) \\
& =\frac{\sigma^{2}}{\left(1-\rho^{2}\right)\left(1-(1-\delta)^{2}\right)}\left[\frac{1+\rho(1-\delta)}{1-\rho(1-\delta)}\right]
\end{aligned}
$$

Therefore

$$
\mathscr{V}_{i}=b_{i}^{2} \frac{\sigma^{2}}{1-\rho^{2}}+c_{i}^{2} \frac{\sigma^{2}}{\left(1-\rho^{2}\right)\left(1-(1-\delta)^{2}\right)}\left[\frac{1+\rho(1-\delta)}{1-\rho(1-\delta)}\right]-2 c_{i} b_{i} \frac{\sigma^{2}}{(1-\rho(1-\delta))\left(1-\rho^{2}\right)}
$$

Hence we have to study the convergence of the series

$$
\sum_{i=1}^{\infty} \beta^{i} \exp \left(a_{i}-c_{i} \frac{\bar{\gamma}}{\delta}+\frac{\sigma^{2}}{2\left(1-\rho^{2}\right)}\left(b_{i}^{2}+\frac{1+\rho(1-\delta)}{(1-\rho(1-\delta))\left(1-(1-\delta)^{2}\right)} c_{i}^{2}-\frac{2 b_{i} c_{i}}{1-\rho(1-\delta)}\right)\right)
$$

Defining

$$
w_{i}=\beta^{i} \exp \left(a_{i}-c_{i} \frac{\bar{\gamma}}{\delta}+\frac{\sigma^{2}}{2\left(1-\rho^{2}\right)}\left(b_{i}^{2}+\frac{1+\rho(1-\delta)}{(1-\rho(1-\delta))\left(1-(1-\delta)^{2}\right)} c_{i}^{2}-\frac{2 b_{i} c_{i}}{1-\rho(1-\delta)}\right)\right)
$$

the series rewrites $\sum_{i=1}^{\infty} w_{i}$, whose convergence properties can be studied relying on the ratio test.

$\left|\frac{w_{i+1}}{w_{i}}\right|=\beta \exp \left(\Delta a_{i+1}-\Delta c_{i+1} \frac{\bar{\gamma}}{\delta}+\frac{\sigma^{2}}{2\left(1-\rho^{2}\right)}\left(\Delta b_{i+1}^{2}+\frac{1+\rho(1-\delta)}{(1-\rho(1-\delta))\left(1-(1-\delta)^{2}\right)} \Delta c_{i+1}^{2}-\frac{2 \Delta\left(b_{i+1} c_{i+1}\right)}{1-\rho(1-\delta)}\right)\right)$

Given the previously given definition of $a_{i}, b_{i}$ and $c_{i}$, we have

$$
\begin{aligned}
\Delta a_{i+1}= & (1-\theta) \bar{\gamma}\left[(1-\varphi)+\varphi(1-\delta)^{i}\right]+(1-\theta)^{2} \frac{\sigma^{2}}{2}\left\{\left(\frac{1-\varphi}{1-\rho}\right)^{2}\left(1-2 \rho^{i+1}+\rho^{2(i+1)}\right)\right. \\
& +2 \frac{\varphi(1-\varphi)}{(1-\rho)(1-\delta-\rho)}\left((1-\delta)^{i+1}-\rho^{i+1}-(\rho(1-\delta))^{i+1}+\rho^{2(i+1)}\right) \\
& \left.+\frac{\varphi^{2}}{(1-\delta-\rho)^{2}}\left((1-\delta)^{2(i+1)}-2(\rho(1-\delta))^{i+1}+\rho^{2(i+1)}\right)\right\} \\
\Delta b_{i+1}^{2}= & (1-\theta)^{2}\left[\left(\frac{\rho(1-\varphi)}{1-\rho}\right)^{2}\left(2 \rho^{i}(1-\rho)-\rho^{2 i}\left(1-\rho^{2}\right)\right)\right. \\
& +\left(\frac{\varphi \rho}{1-\delta-\rho}\right)^{2}\left(2(\rho(1-\delta))^{i}(1-\rho(1-\delta))-(1-\delta)^{2}\left(1-(1-\delta)^{2}\right)-\rho^{2 i}\left(1-\rho^{2}\right)\right) \\
& \left.+\frac{2 \rho^{2} \varphi(1-\delta)}{(1-\rho)(1-\delta-\rho)}\left(\rho^{i}(1-\rho)-\delta(1-\delta)^{i}+(\rho(1-\delta))^{i}(1-\rho(1-\delta))-\rho^{2 i}\left(1-\rho^{2}\right)\right)\right] \\
\Delta c_{i+1}^{2}= & (\varphi(1-\theta))^{2}\left(2 \delta(1-\delta)^{i}-(1-\delta)^{2 i}\left(1-(1-\delta)^{2}\right)\right) \\
\Delta\left(b_{i} c_{i}\right)= & \varphi(1-\theta)^{2}\left[(1-\varphi) \rho^{i+1}+\frac{\varphi \rho}{1-\delta-\rho}\left(\rho^{i}(1-\rho)-\delta(1-\delta)^{i}\right)\right. \\
& -\frac{\rho(1-\varphi)}{1-\rho}\left(\rho^{i}(1-\rho)+\delta(1-\delta)^{i}-(\rho(1-\delta))^{i}(1-\rho(1-\delta))\right) \\
& \left.-\frac{\varphi \rho}{1-\delta-\rho}\left((\rho(1-\delta))^{i}(1-\rho(1-\delta))-(1-\delta)^{2 i}\left(1-(1-\delta)^{2}\right)\right)\right]
\end{aligned}
$$


Then note that

$$
\begin{aligned}
& \lim _{i \rightarrow \infty} \Delta a_{i+1}=(1-\theta) \bar{\gamma}(1-\varphi)+(1-\theta)^{2} \frac{\sigma^{2}}{2}\left(\frac{1-\varphi}{1-\rho}\right)^{2} \\
& \lim _{i \rightarrow \infty} \Delta c_{i+1}=0 \\
& \lim _{i \rightarrow \infty} \Delta b_{i+1}^{2}=0 \\
& \lim _{i \rightarrow \infty} \Delta c_{i+1}^{2}=0 \\
& \lim _{i \rightarrow \infty} \Delta\left(b_{i+1} c_{i+1}\right)=0
\end{aligned}
$$

This implies that

$$
\lim _{i \rightarrow \infty}\left|\frac{w_{i+1}}{w_{i}}\right|=(1-\theta) \bar{\gamma}(1-\varphi)+(1-\theta)^{2} \frac{\sigma^{2}}{2}\left(\frac{1-\delta}{1-\rho}\right)^{2} \equiv r
$$

Therefore, following proposition 5 , the average of the price-dividend ratio converges to a constant if and only if $r<1$.

We now examine the autocovariances of the ratio. As just proven, the price-dividend ratio is finite for $r<1$. Therefore, it is sufficient to show that $\mathbb{E}\left(v_{t} v_{t-k}\right)$ is finite for all $k$. The idea here is to provide an upper bound for this quantity. If the process is stationary it has to be the case that $\mathbb{E}\left(v_{t} v_{t-k}\right) \leqslant \mathbb{E}\left(v_{t}^{2}\right)$.

We want to compute

$$
\begin{aligned}
\mathbb{E}\left(v_{t}^{2}\right) & =\mathbb{E}\left(\sum_{i=1}^{\infty} \sum_{j=1}^{\infty} \beta^{i+j} \exp \left(\left(a_{i}+a_{j}\right)+\left(b_{i}+b_{j}\right)\left(\gamma_{t}-\bar{\gamma}\right)+\left(c_{i}+c_{j}\right) z_{t}\right)\right. \\
& =\sum_{i=1}^{\infty} \sum_{j=1}^{\infty} \beta^{i+j} \mathbb{E}\left(\exp \left(\left(a_{i}+a_{j}\right)+\left(b_{i}+b_{j}\right)\left(\gamma_{t}-\bar{\gamma}\right)+\left(c_{i}+c_{j}\right) z_{t}\right)\right.
\end{aligned}
$$

By the $\log$-normality of $\gamma_{t}$, we know that

$$
\mathbb{E}\left(\exp \left(\left(a_{i}+a_{j}\right)+\left(b_{i}+b_{j}\right)\left(\gamma_{t}-\bar{\gamma}\right)+\left(c_{i}+c_{j}\right) z_{t}\right)=\exp \left(\mathscr{E}_{i, j}+\frac{\mathscr{V}_{i, j}}{2}\right)\right.
$$

where

$$
\mathscr{E}_{i, j}=\mathbb{E}\left(a_{i}+a_{j}+\left(b_{i}+b_{j}\right)\left(\gamma_{t}-\bar{\gamma}\right)+\left(c_{i}+c_{j}\right) z_{t}\right)=a_{i}+a_{j}+\left(c_{i}+c_{j}\right) \mathbb{E}\left(z_{t}\right)
$$

and

$$
\begin{aligned}
\mathscr{V}_{i} & =\operatorname{Var}\left(a_{i}+a_{j}+\left(b_{i}+b_{j}\right)\left(\gamma_{t}-\bar{\gamma}\right)+\left(c_{i}+c_{j}\right) z_{t}\right) \\
& =\left(b_{i}+b_{j}\right) \frac{\sigma^{2}}{1-\rho^{2}}+\left(c_{i}+c_{j}\right) \operatorname{Var}\left(z_{t}\right)+2\left(b_{i}+b_{j}\right)\left(c_{i}+c_{j}\right) \operatorname{Cov}\left(z_{t}, \gamma_{t}\right)
\end{aligned}
$$

From the first part of the proof, we know that

$$
\begin{aligned}
\mathbb{E}\left(z_{t}\right) & =-\frac{\bar{\gamma}}{\delta} \\
\operatorname{Cov}\left(z_{t}, \gamma_{t}\right) & =-\frac{\sigma^{2}}{(1-\rho(1-\delta))\left(1-\rho^{2}\right)} \\
\operatorname{Var}\left(z_{t}\right) & =\frac{\sigma^{2}}{\left(1-\rho^{2}\right)\left(1-(1-\delta)^{2}\right)}\left[\frac{1+\rho(1-\delta)}{1-\rho(1-\delta)}\right]
\end{aligned}
$$


Using the definition of $a_{k}, b_{k}$ and $c_{k}, k=i, j$, it is straightforward - although tedious - to show that

$$
\mathscr{E}_{i, j}=\left[(1-\theta)(1-\varphi) \bar{\gamma}+\left(\frac{1-\theta}{1-\rho}\right)^{2} \frac{\sigma^{2}}{2}(1-\varphi)^{2}\right](i+j)+(1-\theta)^{2} \frac{\sigma^{2}}{2} \Psi_{i j}
$$

where

$$
\begin{aligned}
\Psi_{i j} \equiv & \frac{\rho^{2}}{1-\rho^{2}}\left(\frac{1-\varphi}{1-\rho}+\frac{\varphi}{1-\delta-\rho}\right)^{2}\left(2-\rho^{2 i}-\rho^{2 j}\right)+\frac{\varphi^{2}(1-\delta)^{2}}{(1-\delta-\rho)\left(1-(1-\delta)^{2}\right)}\left(2-(1-\delta)^{2 i}-(1-\delta)^{2 j}\right) \\
& -\frac{2 \rho \varphi(1-\delta)}{(1-\rho(1-\delta))(1-\delta-\rho)}\left(\frac{1-\varphi}{1-\rho}+\frac{\varphi}{1-\delta-\rho}\right)\left(2-(\rho(1-\delta))^{i}-(\rho(1-\delta))^{j}\right) \\
& -2 \frac{\rho}{1-\rho} \frac{1-\varphi}{1-\rho}\left(\frac{1-\varphi}{1-\rho}+\frac{\varphi}{1-\delta-\rho}\right)\left(2-\rho^{i}-\rho^{j}\right)+2 \frac{1-\delta}{\delta} \frac{\varphi(1-\varphi)}{(1-\rho)(1-\delta-\rho)}\left(2-(1-\delta)^{i}-(1-\delta)^{j}\right)
\end{aligned}
$$

and

$$
\mathscr{V}_{i, j}=(1-\theta)^{2} \sigma^{2} \frac{\rho^{2}}{1-\rho^{2}} \mathscr{V}_{i, j}^{1}+\frac{\varphi^{2}(1-\theta)^{2} \sigma^{2}}{\left(1-\rho^{2}\right)\left(1-(1-\delta)^{2}\right)}\left[\frac{1+\rho(1-\delta)}{1-\rho(1-\delta)}\right] \mathscr{V}_{i, j}^{2}-\frac{\varphi(1-\theta)^{2} \sigma^{2}}{(1-\rho(1-\delta))\left(1-\rho^{2}\right)} \mathscr{V}_{i, j}^{3}
$$

where

$$
\begin{aligned}
\mathscr{V}_{i, j}^{1} \equiv & 4\left(\frac{1-\varphi}{1-\rho}\right)^{2}+\left(\frac{\varphi}{1-\delta-\rho}\right)^{2}\left((1-\delta)^{2 i}+2(1-\delta)^{i+j}+(1-\delta)^{2 j}\right) \\
& +\left(\frac{1-\varphi}{1-\rho}+\frac{\varphi}{1-\delta-\rho}\right)^{2}\left(\rho^{2 i}+2 \rho^{i+j}+\rho^{2 j}\right)-4 \frac{1-\varphi}{1-\rho}\left(\frac{1-\varphi}{1-\rho}+\frac{\varphi}{1-\delta-\rho}\right)\left(\rho^{i}+\rho^{j}\right) \\
& +4 \frac{\varphi(1-\varphi)}{(1-\rho)(1-\delta-\rho)}\left((1-\delta)^{i}+(1-\delta)^{j}\right) \\
& -2 \frac{\varphi}{1-\delta-\rho}\left(\frac{1-\varphi}{1-\rho}+\frac{\varphi}{1-\delta-\rho}\right)\left((\rho(1-\delta))^{i}+(\rho(1-\delta))^{j}+\rho^{i}(1-\delta)^{j}+\rho^{j}(1-\delta)^{i}\right)
\end{aligned}
$$

and

$$
\mathscr{V}_{i, j}^{2} \equiv 4+(1-\delta)^{2 i}+(1-\delta)^{2 j}-4\left((1-\delta)^{i}+(1-\delta)^{j}\right)+2(1-\delta)^{i+j}
$$

and

$$
\begin{aligned}
\mathscr{V}_{i, j}^{3} \equiv & 4 \frac{1-\varphi}{1-\rho}+2 \frac{\varphi}{1-\delta-\rho}\left((1-\delta)^{i}+(1-\delta)^{j}\right)-2\left(\frac{1-\varphi}{1-\rho}+\frac{\varphi}{1-\delta-\rho}\right)\left(\rho^{i}+\rho^{j}\right) \\
& -2 \frac{1-\varphi}{1-\rho}\left((1-\delta)^{i}+(1-\delta)^{j}\right)-\frac{\varphi}{1-\delta-\rho}\left((1-\delta)^{2 i}+2(1-\delta)^{i+j}+(1-\delta)^{j}\right) \\
& \left(\frac{1-\varphi}{1-\rho}+\frac{\varphi}{1-\delta-\rho}\right)\left((\rho(1-\delta))^{i}+(\rho(1-\delta))^{j}+\rho^{i}(1-\delta)^{j}+\rho^{j}(1-\delta)^{i}\right)
\end{aligned}
$$

Using the triangular inequality, we have $\Psi_{i j} \leqslant \bar{\Psi}$ where

$$
\begin{aligned}
\bar{\Psi} \equiv & 4 \frac{\rho^{2}}{1-\rho^{2}}\left(\frac{1-\varphi}{1-\rho}+\frac{\varphi}{|1-\delta-\rho|}\right)^{2}+4 \frac{\varphi^{2}(1-\delta)^{2}}{|1-\delta-\rho|\left(1-(1-\delta)^{2}\right)} \\
& +\frac{8 \rho \varphi(1-\delta)}{(1-\rho(1-\delta))|1-\delta-\rho|}\left(\frac{1-\varphi}{1-\rho}+\frac{\varphi}{|1-\delta-\rho|}\right) \\
& +8 \frac{\rho}{1-\rho} \frac{1-\varphi}{1-\rho}\left(\frac{1-\varphi}{1-\rho}+\frac{\varphi}{|1-\delta-\rho|}\right)+8 \frac{1-\delta}{\delta} \frac{\varphi(1-\varphi)}{(1-\rho)|1-\delta-\rho|}
\end{aligned}
$$


Likewise, the triangular inequality implies that

$$
\begin{aligned}
\mathscr{V}_{i, j}^{1} \leqslant & 4\left(\frac{1-\varphi}{1-\rho}\right)^{2}+4\left(\frac{\varphi}{|1-\delta-\rho|}\right)^{2}+4\left(\frac{1-\varphi}{1-\rho}+\frac{\varphi}{|1-\delta-\rho|}\right)^{2}+8 \frac{1-\varphi}{1-\rho}\left(\frac{1-\varphi}{1-\rho}+\frac{\varphi}{|1-\delta-\rho|}\right) \\
& +8 \frac{\varphi(1-\varphi)}{(1-\rho)(|1-\delta-\rho|)}+8 \frac{\varphi}{|1-\delta-\rho|}\left(\frac{1-\varphi}{1-\rho}+\frac{\varphi}{|1-\delta-\rho|}\right) \\
\leqslant & 16\left(\frac{1-\varphi}{1-\rho}+\frac{\varphi}{|1-\delta-\rho|}\right)^{2}
\end{aligned}
$$

similarly

$\mathscr{V}_{i, j}^{2} \leqslant 16$

and

$$
\begin{aligned}
\mathscr{V}_{i, j}^{3} & \leqslant 4 \frac{1-\varphi}{1-\rho}+4 \frac{\varphi}{|1-\delta-\rho|}+4\left(\frac{1-\varphi}{1-\rho}+\frac{\varphi}{|1-\delta-\rho|}\right)+4 \frac{1-\varphi}{1-\rho}+4 \frac{\varphi}{|1-\delta-\rho|}+4\left(\frac{1-\varphi}{1-\rho}+\frac{\varphi}{|1-\delta-\rho|}\right) \\
& \leqslant 16\left(\frac{1-\varphi}{1-\rho}+\frac{\varphi}{|1-\delta-\rho|}\right)
\end{aligned}
$$

Therefore, we have $\mathscr{V}_{i, j} \leqslant \overline{\mathscr{V}}$, where

$$
\begin{aligned}
\overline{\mathscr{V}} \equiv & 16(1-\theta)^{2} \sigma^{2} \frac{\rho^{2}}{1-\rho^{2}}\left(\frac{1-\varphi}{1-\rho}+\frac{\varphi}{|1-\delta-\rho|}\right)^{2}+16 \frac{\varphi^{2}(1-\theta)^{2} \sigma^{2}}{\left(1-\rho^{2}\right)\left(1-(1-\delta)^{2}\right)}\left[\frac{1+\rho(1-\delta)}{1-\rho(1-\delta)}\right] \\
& +16 \frac{\varphi(1-\theta)^{2} \sigma^{2}}{(1-\rho(1-\delta))\left(1-\rho^{2}\right)}\left(\frac{1-\varphi}{1-\rho}+\frac{\varphi}{|1-\delta-\rho|}\right)
\end{aligned}
$$

Hence, we have that

$$
\begin{aligned}
\mathbb{E}\left(v_{t}^{2}\right) & \leqslant \sum_{i=1}^{\infty} \sum_{j=1}^{\infty} \beta^{i+j} \exp \left(\left[(1-\theta)(1-\varphi) \bar{\gamma}+\left(\frac{1-\theta}{1-\rho}\right)^{2} \frac{\sigma^{2}}{2}(1-\varphi)^{2}\right](i+j)\right) \exp \left((1-\theta)^{2} \frac{\sigma^{2}}{2} \bar{\Psi}+\frac{\overline{\mathscr{V}}}{2}\right) \\
& \leqslant \exp \left((1-\theta)^{2} \frac{\sigma^{2}}{2} \bar{\Psi}+\frac{\overline{\mathscr{V}}}{2}\right) \sum_{i=1}^{\infty} \sum_{j=1}^{\infty} r^{i+j} \\
& \leqslant \exp \left((1-\theta)^{2} \frac{\sigma^{2}}{2} \bar{\Psi}+\frac{\overline{\mathscr{V}}}{2}\right) r \sum_{k=1}^{\infty} n r^{n}
\end{aligned}
$$

As long as $r<1$, the series $\sum_{k=1}^{\infty} n r^{n}$ converges, such that in this case $\mathbb{E} v_{t}^{2}<\infty$.

We can now consider the autocovariance terms

$$
\begin{aligned}
\mathbb{E}\left(v_{t} v_{t-k}\right)=\sum_{i=1}^{\infty} \sum_{j=1}^{\infty} \beta^{i+j} \exp [ & a_{i}+a_{j}-\left(c_{i}+c_{j}\right) \frac{\bar{\gamma}}{\delta}+\frac{1}{2}\left(b_{i}^{2} \operatorname{Var}\left(\gamma_{t}\right)+b_{j}^{2} \operatorname{Var}\left(\gamma_{t-k}\right)+c_{i}^{2} \operatorname{Var}\left(z_{t}\right)\right. \\
& +c_{j}^{2} \operatorname{Var}\left(z_{t-k}\right)+2 b_{i} b_{j} \operatorname{Cov}\left(\gamma_{t}, \gamma_{t-k}\right)+2 b_{i} c_{i} \operatorname{Cov}\left(\gamma_{t}, z_{t}\right)+2 b_{i} c_{j} \operatorname{Cov}\left(\gamma_{t}, z_{t-k}\right) \\
& \left.\left.+2 b_{j} c_{i} \operatorname{Cov}\left(\gamma_{t-k}, z_{t}\right)+2 b_{j} c_{j} \operatorname{Cov}\left(\gamma_{t-k}, z_{t-k}\right)+2 c_{i} c_{j} \operatorname{Cov}\left(z_{t}, z_{t-k}\right)\right)\right]
\end{aligned}
$$


where $^{8}$

$$
\begin{aligned}
& \operatorname{Cov}\left(\gamma_{t}, \gamma_{t-k}\right)=\rho^{k} \frac{\sigma^{2}}{1-\rho^{2}}=\rho^{k} \operatorname{Var}\left(\gamma_{t}\right) \\
& \operatorname{Cov}\left(z_{t}, z_{t-k}\right)=\frac{\sigma^{2}}{1-\delta-\rho}\left(\frac{\left(1-\rho^{2}\right)(1-\delta)^{k+1}-\left(1-(1-\delta)^{2}\right) \rho^{k+1}}{(1-\rho(1-\delta))\left(1-\rho^{2}\right)\left(1-(1-\delta)^{2}\right)}\right) \Phi_{z z, k} \operatorname{Var}\left(z_{t}\right) \\
& \operatorname{Cov}\left(z_{t}, \gamma_{t-k}\right)=\frac{\sigma^{2}}{1-\delta-\rho}\left(\frac{\rho^{k+1}}{1-\rho^{2}}-\frac{(1-\delta)^{k+1}}{1-\rho(1-\delta)}\right)=\Phi_{z \gamma, k} \operatorname{Cov}\left(z_{t}, \gamma_{t}\right) \\
& \operatorname{Cov}\left(\gamma_{t}, z_{t-k}\right)=-\frac{\sigma^{2}}{\left(1-\rho^{2}\right)(1-\delta(1-\delta))} \rho^{k}=\rho^{k} \operatorname{Cov}\left(\gamma_{t}, z_{t}\right)
\end{aligned}
$$

with

$$
\begin{gathered}
\Phi_{z z, k}=\frac{(1-\delta)\left(1-\rho^{2}\right)(1-\delta)^{k}-\rho\left(1-(1-\delta)^{2}\right) \rho^{k}}{\left(1-\rho^{2}\right)(1-\delta)-\left(1-(1-\delta)^{2}\right) \rho} \\
\Phi_{z \gamma, k}=\frac{(1-\delta)\left(1-\rho^{2}\right)(1-\delta)^{k}-\rho(1-\rho(1-\delta)) \rho^{k}}{\left(1-\rho^{2}\right)(1-\delta)-\rho(1-\rho(1-\delta))}
\end{gathered}
$$

Note that, by construction, we have $\left|\Phi_{z z, k}\right|<1$ and $\left|\Phi_{z \gamma, k}\right|<1$.

$\mathbb{E}\left(v_{t} v_{t-k}\right)$ can then be rewritten as

$$
\mathbb{E}\left(v_{t} v_{t-k}\right)=\sum_{i=1}^{\infty} \sum_{j=1}^{\infty} \beta^{i+j} \exp \left[a_{i}+a_{j}-\left(c_{i}+c_{j}\right) \frac{\bar{\gamma}}{\delta}+\frac{1}{2} \mathscr{V}_{i, j, k}\right]
$$

where

$$
\begin{aligned}
\mathscr{V}_{i, j, k} \equiv & \left(b_{i}^{2}+b_{j}^{2}+2 b_{i} b_{j} \rho^{k}\right) \operatorname{Var}\left(\gamma_{t}\right)+\left(c_{i}^{2}+c_{j}^{2}+2 c_{i} c_{j} \Phi_{z z, k}\right) \operatorname{Var}\left(z_{t}\right) \\
& +2\left(b_{i} c_{i}+b_{j} c_{j}+b_{i} c_{j} \rho^{k}+c_{j} c_{i} \Phi_{z \gamma, k}\right) \operatorname{Cov}\left(\gamma_{t}, z_{t}\right)
\end{aligned}
$$

Since $b_{i} b_{j}>0$ and $|\rho|<1$, we have $b_{i}^{2}+b_{j}^{2}+2 b_{i} b_{j} \rho^{k} \leqslant\left(b_{i}+b_{j}\right)^{2}$. Likewise $c_{i} c_{j}>0$ and $\left|\Phi_{z z, k}\right|<1$, so that $\left(c_{i}^{2}+c_{j}^{2}+2 c_{i} c_{j} \Phi_{z z, k}\right) \leqslant\left(c_{i}+c_{j}\right)^{2}$. Finally, we have $b_{n} c_{\ell}>0,(n, \ell) \in\{i, j\} \times\{i, j\}$ and both $|\rho|<1$ and $\left|\Phi_{z \gamma, k}\right|<1$, such that $\left(b_{i} c_{i}+b_{j} c_{j}+b_{i} c_{j} \rho^{k}+c_{j} c_{i} \Phi_{z \gamma, k}\right) \leqslant\left(b_{i}+b_{j}\right)\left(c_{i}+c_{j}\right)$. This implies that

$$
\left|\mathscr{V}_{i, j, k}\right| \leqslant\left(b_{i}+b_{j}\right)^{2} \operatorname{Var}\left(\gamma_{t}\right)+\left(c_{i}+c_{j}\right)^{2} \operatorname{Var}\left(z_{t}\right)+\left(b_{i}+b_{j}\right)\left(c_{i}+c_{j}\right)\left|\operatorname{Cov}\left(z_{t}, \gamma_{t}\right)\right|
$$

Hence $\mathbb{E} v_{t}^{2}$ is un upper bound for $\mathbb{E}\left(v_{t} v_{t-k}\right)$. Therefore, as $\mathbb{E} v_{t}^{2}$ is finite for $r<1$, so is $\mathbb{E}\left(v_{t} v_{t-k}\right)$.

${ }^{8}$ These quantities can be straightforwardly obtained from the Wold representations of $\gamma_{t}$ and $z_{t}$ :

$$
\gamma_{t}=\bar{\gamma}+\sum_{i=0}^{\infty} \rho^{i} \varepsilon_{t-i} \text { and } z_{t}=\sum_{i=0}^{\infty} \frac{\rho^{i+1}-(1-\delta)^{i+1}}{1-\delta-\rho} \varepsilon_{t-i}
$$

